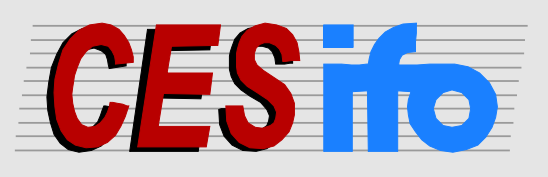

\title{
Working
}

Papers

www.cesifo.org/wp

\section{Optimal Fiscal Action in an Economy with Sovereign Premia and without Monetary Independence: An Application to Italy}

\author{
Apostolis Philippopoulos \\ Petros Varthalitis \\ Vanghelis Vassilatos
}

\begin{abstract}
CESIFO WORKING PAPER NO. 4199
CATEGORY 6: FisCAL POLICY, MACROECONOMICS AND GROWTH

APRIL 2013
\end{abstract}

Presented at CESifo Area Conference on Macro, Money \& International Finance, February 2013

An electronic version of the paper may be downloaded

- from the SSRN website:

- from the RePEc website:

- from the CESifo website:

wWw.SSRN.com

www.RePEc.org

www.CESifo-group.org/wp

\section{CESifo}




\title{
Optimal Fiscal Action in an Economy with Sovereign Premia and without Monetary Independence: An Application to Italy
}

\begin{abstract}
We welfare rank various tax-spending policies. The setup is a New Keynesian model of a semi-small open economy featuring sovereign risk premia and loss of monetary policy independence. The model is calibrated to match data from the Italian economy 2001-2011. We compute various optimized state-contingent tax-spending policy rules when the policy aim is shock stabilization and/or debt consolidation.
\end{abstract}

JEL-Code: E600, F300, H600.

Keywords: feedback policy rules, New Keynesian, sovereign premia.

\author{
Apostolis Philippopoulos \\ Department of Economics \\ Athens University of Economics and Business \\ Greece-10434 Athens \\ aphil@aueb.gr
}

\author{
Petros Varthalitis \\ Department of Economics \\ Athens University of Economics \\ and Business \\ Greece-10434 Athens \\ pvarthalitis@aueb.gr
}

\author{
Vanghelis Vassilatos \\ Department of Economics \\ Athens University of Economics \\ and Business \\ Greece-10434 Athens \\ vvassila@aueb.gr
}

March 27, 2013

We are grateful to Dimitris Papageorgiou. We also thank Kostas Angelopoulos, Fabrice Collard, Harris Dellas, George Economides, Jim Malley, Evi Pappa and Elias Tzavalis. We thank the Bank of Greece, and in particular Heather Gibson and George Tavlas, for their support and hospitality when this paper started. We have benefited from comments by seminar participants at the CESifo Area Conference on Macroeconomics, Munich, February 2013, as well as at the Athens University of Economics and Business and the Bank of Greece. The second author is grateful to the Irakleitos Research Program for financing his doctoral studies. Any errors are ours. 


\section{Introduction}

Following the world financial and economic crisis in 2008, several countries are facing sovereign risk premia. This is particularly the case in South European countries, where high public debt coexists with an economic downturn. At the same time, as members of the single currency, these countries cannot use monetary-exchange rate policy to counter the recession or reduce the real burden of domestic public debt. Thus, the only macroeconomic tool available is fiscal policy. What is the best use of fiscal policy? Which tax-spending policy instrument to use? Which are the operating targets, that these policy instruments should react to, and how strong this reaction should be? Do results change depending on whether the policy aim is to stabilize the economy against shocks or to reduce public debt and sovereign premia over time?

This paper welfare ranks various fiscal policies in light of the above. The setup is the standard New Keynesian model extended into a small open-economy setting with sovereign risk premia. These premia mean that the interest rate, at which the country borrows from the world capital market, increases with government's total debt (for empirical evidence, see e.g. Obstfeld and Taylor, 2003, and European Commission, 2011; for a review of the theoretical literature, see e.g. Schmitt-Grohé and Uribe, 2003). We focus on a monetary policy regime in which the semi-small open economy fixes the exchange rate and, at the same time, loses monetary policy independence; this mimics being member in a currency union. Hence, the only macroeconomic tool left is fiscal policy. We then allow public spending and the main types of taxes to respond to the state of public debt and to the output gap and eventually welfare rank different policies.

The model is calibrated to match fiscal and public finance data from the Italian economy during 2001-2011. We choose Italy because it exhibits most of the features discussed in the opening paragraph above. It thus looks as a natural choice to quantify our model. To solve the model and, in particular, to solve for welfare-maximizing policy, we adopt the methodology of Schmitt-Grohé and Uribe (2004 and 2007), in the sense that we take a second-order approximation to both the equilbrium conditions and the welfare criterion. In turn, we compute the welfare-maximizing values of various feedback policy rules. This enables us to welfare rank alternative policies in a stochactic setup.

Our main results are as follows. First, contrary to the conventional belief that it is better to use public spending rather than taxes for shock stabilization and/or debt consolidation, this is not the case in a semi-small open economy with sovereign premia. This happens because sovereign premia introduce extra distortions/wedges in relative prices and thus tax rates are more suitable, than public spending, to offset these distortions/wedges (see also the discussion 
in Wren-Lewis, 2010). This is a second-best argument.

Second, consumption taxes are the best, or the least distorting, policy instrument to use. Capital taxes can also score well in normal times, during which the issue is shock stabilization only, but are by far the worst choice when drastic intervention is needed as in the case of debt consolidation. These results hold when we are far sighted, in the sense that we care about long time horizons. If, for some reason, behavior is short termist, then capital taxes are the least distorting instrument to use for debt consolidation. This follows the Ramsey-Chamley logic. Namely, in the very short run, the capital tax can work like a capital levy on existing wealth which is not so distorting relative to other taxes. However, as we start becoming more far sighted, the capital tax proves to be a very bad idea giving by far the worst outcomes.

Third, debt consolidation is, other things equal, welfare improving (except, as said, if we use a very distorting instrument like capital taxes). This is despite the fact that debt consolidation comes at the cost of lower public spending and/or higher taxes during the early phase of the transition period. Also, the duration of the debt consolidation period, and so how quickly the debt should be brought down, depends on which fiscal instrument we use. The more distorting is the instrument used, the longer the period should be.

Fourth, fiscal policy instruments should react to both public debt imbalances and the output gap. Thus, fiscal activism is productive in general (this is different from e.g. Taylor, 2009, and Feldstein, 2009). Of course, which reaction dominates (to debt or to output) is what determines the net change in the policy instruments. In normal times during which shock stabilization is the policy concern, our impulse response functions imply that the fiscal instruments should counter the recession first and only in turn address debt problems over time. But, if drastic policy is needed to reduce public debt and sovereign premia over time, then the net changes in fiscal instruments should be driven by the reaction to debt and, as said, this is welfare improving (except if we use a very distorting instrument like capital taxes).

Fifth, the fictional case, in which Italy would be free to follow an independent monetaryexchange rate policy, seems to be welfare superior in the case of debt consolidation, but this result needs to be treated with caution. For instance, our model does not include credibity (Barro-Gordon type) problems typically arising under flexible exchange rates in inflation-prone countries like Italy. The inclusion of such problems will weaken the arguments for independent monetary-exchange rate policy.

Our paper is related to at least two strands of literature. First, it is related to a rich and still growing literature on how monetary and fiscal policy instruments react, or should react, 
to the business cycle. ${ }^{1}$ Our paper is also related to the recent literature on fiscal consolidation that usually compares spending cuts versus tax rises needed for debt reduction. ${ }^{2}$ Nevertheless, as far as we know, there have not been any previous attempts to welfare rank the main taxspending instruments in a New Keynesian open economy with sovereign premia and without monetary independence, and study how results change depending on whether the government simply stabilizes the economy from shocks, or also reduces public debt and eliminates premia over time. Also, as said above, to rank alternative policies, we work with optimized feedback policy rules.

The rest of the paper is as follows. Section 2 presents the model. Section 3 presents the data, calibration and the long-run solution. Section 4 explains how we model economic policy. The transition path and the results of the paper are in sections 5 and 6 . Section 7 closes the paper. An Appendix includes technical details.

\section{Model}

Consider a model of a small open economy, which is extended to include endogenous sovereign risk premia and state-contingent policy rules. The rest of the setup is the standard New Keynesian model of a small open economy with domestic and imported goods featuring imperfect competition and nominal rigidities (see e.g. Gali and Monacelli, 2005, 2008). That is, as in Calvo (1983), each firm produces a differentiated tradable good for which it sets the price and only a fraction of firms can freely reset their prices in any given period. ${ }^{3}$ Exogenous fluctuations are driven by TFP shocks.

The domestic economy is composed of $N$ identical households indexed by $i=1,2, \ldots, N$, $N$ firms indexed by $h=1,2, \ldots, N$, each one of them producing a differentiated domestically produced tradable good, as well as of monetary and fiscal authorities. Similarly, there are $f=1,2, \ldots, N$ differentiated imported goods produced abroad. Population, $N$, is constant over time.

\footnotetext{
${ }^{1}$ See e.g. Leeper (1991), Schmitt-Grohé and Uribe (2005 and 2007), Kirsanova et al. (2007), Leith and WrenLewis (2008), Batini et al. (2008), Kirsanova et al. (2009), Leeper et al. (2009), Bi (2010), Bi and Kumhof (2011), Kirsanova and Wren-Lewis (2012), Herz and Hohberger (2012), Cantore et al. (2012), Philippopoulos et al. (2012).

${ }^{2}$ See e.g. Forni et al. (2010), Bi et al. (2012), Cogan et al. (2013), Erceg and Linde (2013) and Papageorgiou (2012).

${ }^{3}$ For the New Keynesian model, see the textbooks of Gali (2008) and Wickens (2008).
} 


\subsection{Aggregation and prices}

\subsubsection{Consumption bundles}

Household $i$ 's consumption bundle at $t, c_{i, t}$, consists of domestic and foreign goods as:

$$
c_{i, t}=\frac{\left(c_{i, t}^{H}\right)^{\nu}\left(c_{i, t}^{F}\right)^{1-\nu}}{\nu^{\nu}(1-\nu)^{1-\nu}}
$$

where $c_{i, t}^{H}$ is the composite of domestically produced tradable goods consumed by household $i, c_{i, t}^{F}$ is the composite of imported tradable goods, and $\nu$ is the degree of preference for good produced at home (if $\nu>1 / 2$, there is a home bias).

There are $h=1,2, \ldots, N$ varieties of goods belonging to $c_{i, t}^{H}$, each variety produced monopolistically by one domestic firm $h$. Using a Dixit-Stiglitz aggregator, $c_{i, t}^{H}$ is a composite of goods $h$ :

$$
c_{i, t}^{H}=\left[\sum_{h=1}^{N} \lambda\left[c_{i, t}^{H}(h)\right]^{\frac{\phi-1}{\phi}}\right]^{\frac{\phi}{\phi-1}}
$$

where $\phi>0$ is the elasticity of substitution across goods produced in the domestic country and $\sum_{h=1}^{N} \lambda=1$ are weights (to avoid scale effects, we assume $\lambda=1 / N$ ).

Similarly, there are $f=1,2, \ldots, N$ varieties of goods belonging to $c_{i, t}^{F}$, each variety produced monopolistically by one foreign firm $f$, so that the aggregator for imported goods is:

$$
c_{i, t}^{F}=\left[\sum_{f=1}^{N} \lambda\left[c_{i, t}^{F}(f)\right]^{\frac{\phi-1}{\phi}}\right]^{\frac{\phi}{\phi-1}}
$$

\subsubsection{Consumption expenditure, prices and terms of trade}

Household $i$ 's total consumption expenditure is:

$$
P_{t} c_{i, t}=P_{t}^{H} c_{i, t}^{H}+P_{t}^{F} c_{i, t}^{F}
$$

where $P_{t}$ is the consumer price index $(\mathrm{CPI}), P_{t}^{H}$ is the price index of home tradables, and $P_{t}^{F}$ is the price index of foreign tradables (expressed in domestic currency). In turn, each household's total expenditure on home goods and foreign goods are respectively:

$$
P_{t}^{H} c_{i, t}^{H}=\sum_{h=1}^{N} \lambda P_{t}^{H}(h) c_{i, t}^{H}(h)
$$




$$
P_{t}^{F} c_{i, t}^{F}=\sum_{f=1}^{N} \lambda P_{t}^{F}(f) c_{i, t}^{F}(f)
$$

where $P_{t}^{H}(h)$ is the price of variety $h$ produced at home and $P_{t}^{F}(f)$ is the price of variety $f$ produced abroad, both denominated in domestic currency. We assume that the law of one price holds meaning that each tradable good sells at the same price at home and abroad. Thus, $P_{t}^{F}(f)=S_{t} P_{t}^{H *}(f)$, where $S_{t}$ is the nominal exchange rate (where an increase in $S_{t}$ implies a depreciation) and $P_{t}^{H *}(f)$ is the price of variety $f$ produced abroad denominated in foreign currency. A star denotes the counterpart of a variable or a parameter in the rest-of-the world. Note that the terms of trade are defined as $\frac{P_{t}^{F}}{P_{t}^{H}}\left(=\frac{S_{t} P_{t}^{H *}}{P_{t}^{H}}\right)$, while the real exchange rate is defined as $\frac{S_{t} P_{t}^{*}}{P_{t}} \cdot{ }^{4}$

\subsection{Households}

\subsubsection{Household's problem}

There are $i=1,2, \ldots, . N$ households. Each household $i$ acts competitively to maximize expected lifetime utility:

$$
E_{0} \sum_{t=0}^{\infty} \beta^{t} U\left(c_{i, t}, n_{i, t}, m_{i, t}, g_{t}\right)
$$

where $c_{i, t}$ is $i$ 's consumption bundle as defined above, $n_{i, t}$ is $i$ 's hours of work, $m_{i, t} \equiv \frac{M_{i, t}}{P_{t}}$ is $i$ 's real money holdings, $g_{t}$ is per capita public spending, $0<\beta<1$ is the time discount rate, and $E_{0}$ is the rational expectations operator conditional on the information set.

The period utility function is assumed to be of the form (see also e.g. Gali, 2008):

$$
u_{i, t}\left(c_{i, t}, n_{i, t}, m_{i, t}, g_{t}\right)=\frac{c_{i, t}^{1-\sigma}}{1-\sigma}-\chi_{n} \frac{n_{i, t}^{1+\eta}}{1+\eta}+\chi_{m} \frac{m_{i, t}^{1-\mu}}{1-\mu}+\chi_{g} \frac{g_{t}^{1-\zeta}}{1-\zeta}
$$

where $\chi_{n}, \chi_{m}, \chi_{g}, \sigma, \eta, \mu, \zeta$ are preference parameters. Thus, $\sigma$ is a coefficient of intertemporal subsititution and $\eta$ is the Frisch labour elasticity.

The period budget constraint of each household $i$ expressed in real terms is:

\footnotetext{
${ }^{4}$ For the relation between terms of trade and the real exchange rate, see Benigno and Thoenissen (2003). See also Fahr and Smets (2010) and Wickens (2008, p. 166).
} 


$$
\begin{aligned}
& \left(1+\tau_{t}^{c}\right)\left[\frac{P_{t}^{H}}{P_{t}} c_{i, t}^{H}+\frac{P_{t}^{F}}{P_{t}} c_{i, t}^{F}\right]+\frac{P_{t}^{H}}{P_{t}} x_{i, t}+b_{i, t}+m_{i, t}+\frac{S_{t} P_{t}^{*}}{P_{t}} f_{i, t}^{h}+\frac{\phi^{h}}{2}\left(\frac{S_{t} P_{t}^{*}}{P_{t}} f_{i, t}^{h}-\frac{S P^{*}}{P} f^{h}\right)^{2} \\
= & \left(1-\tau_{t}^{k}\right)\left[r_{t}^{k} \frac{P_{t}^{H}}{P_{t}} k_{i, t-1}+d_{i, t}\right]+\left(1-\tau_{t}^{n}\right) w_{t} n_{i, t}+R_{t-1} \frac{P_{t-1}}{P_{t}} b_{i, t-1}+ \\
& +\frac{P_{t-1}}{P_{t}} m_{i, t-1}+Q_{t-1} \frac{S_{t} P_{t}^{*}}{P_{t}} \frac{P_{t-1}^{*}}{P_{t}^{*}} f_{i, t-1}^{h}-\tau_{i, t}^{l}
\end{aligned}
$$

where $x_{i, t}$ is $i$ 's domestic investment, $b_{i, t}$ is $i$ 's end-of-period real domestic government bonds, $m_{i, t}$ is $i$ 's end-of period real domestic money holdings, $f_{i, t}^{h}$ is $i$ 's end-of-period real internationally traded assets denominated in foreign currency, $r_{t}^{k}$ is the real return to inherited domestic capital, $k_{i, t-1}, d_{i, t}$ is $i$ 's real dividends received by domestic firms, $w_{t}$ is the real wage rate, $R_{t-1} \geq 1$ is the gross nominal return to domestic government bonds between $t-1$ and $t$, $Q_{t-1} \geq 1$ is the gross nominal return to international assets between $t-1$ and $t, \tau_{i, t}^{l}$ are real lump-sum taxes/transfers to each household, and $\tau_{t}^{c}, \tau_{t}^{k}, \tau_{t}^{n}$ are tax rates on consumption, capital income and labour income respectively. Thus, small letters denote real variables, namely, $m_{i, t} \equiv \frac{M_{i, t}}{P_{t}}, b_{i, t} \equiv \frac{B_{i, t}}{P_{t}}, f_{i, t}^{h} \equiv \frac{F_{i, t}^{h}}{P_{t}^{*}}, w_{t} \equiv \frac{W_{t}}{P_{t}}, d_{i, t} \equiv \frac{D_{i, t}}{P_{t}}, \tau_{i, t}^{l} \equiv \frac{T_{i, t}^{l}}{P_{t}}$, where capital letters denote nominal variables. The parameter $\phi^{h} \geq 0$ captures transaction costs related to foreign assets, where variables without time subscripts denote long-run values (these costs are not important to the main results but help the model with the data - see also below).

The motion of physical capital for each household $i$ is:

$$
k_{i, t}=(1-\delta) k_{i, t-1}+x_{i, t}-\frac{\xi}{2}\left(\frac{k_{i, t}}{k_{i, t-1}}-1\right)^{2} k_{i, t-1}
$$

where $0<\delta<1$ is the depreciation rate of capital and $\xi \geq 0$ is a parameter capturing adjustment costs related to physical capital.

\subsubsection{Household's optimality conditions}

Each household $i$ acts competitively taking prices and policy as given. Following the literature, to solve the household's problem, we follow a two-step procedure. Thus, we first suppose that the household determines its desired consumption of composite goods, $c_{i, t}^{H}$ and $c_{i, t}^{F}$, and, in turn, chooses how to distribute its purchases of individual varieties, $c_{i, t}^{H}(h)$ and $c_{i, t}^{F}(f)$.

The first-order conditions of each $i$ include the budget constraints above and also:

$$
\begin{gathered}
\frac{\partial u_{i, t}}{\partial c_{i, t}} \frac{\partial c_{i, t}}{\partial c_{i, t}^{H}} \frac{P_{t}}{P_{t}^{H}\left(1+\tau_{t}^{c}\right)}= \\
\beta E_{t} \frac{\partial u_{i, t+1}}{\partial c_{i, t+1}} \frac{\partial c_{i, t+1}}{\partial c_{i, t+1}^{H}} \frac{P_{t+1}}{P_{t+1}^{H}\left(1+\tau_{t+1}^{c}\right)} R_{t} \frac{P_{t}}{P_{t+1}}
\end{gathered}
$$




$$
\begin{aligned}
& \frac{\partial u_{i, t}}{\partial c_{i, t}} \frac{\partial c_{i, t}}{\partial c_{i, t}^{H}} \frac{P_{t}}{P_{t}^{H}\left(1+\tau_{t}^{c}\right)} \frac{S_{t} P_{t}^{*}}{P_{t}}\left[1+\phi^{h}\left(\frac{S_{t} P_{t}^{*}}{P_{t}} f_{t}^{h}-\frac{S P^{*}}{P} f^{h}\right)\right] \\
& =\beta E_{t} \frac{\partial u_{i, t+1}}{\partial c_{i, t+1}} \frac{\partial c_{i, t+1}}{\partial c_{t+1}^{H}} \frac{P_{t+1}}{P_{t+1}^{H}\left(1+\tau_{t+1}^{c}\right)} Q_{t} \frac{S_{t+1} P_{t+1}^{*}}{P_{t+1}} \frac{P_{t}^{*}}{P_{t+1}^{*}} \\
& \frac{\partial u_{i, t}}{\partial c_{i, t}} \frac{\partial c_{i, t}}{\partial c_{i, t}^{H}} \frac{1}{\left(1+\tau_{t}^{c}\right)}\left\{1-\xi\left(\frac{k_{i, t}}{k_{i, t-1}}-1\right)\right\} \\
& =\beta E_{t} \frac{\partial u_{i, t+1}}{\partial c_{i, t+1}} \frac{\partial c_{i, t+1}}{\partial c_{i, t+1}^{H}} \frac{1}{\left(1+\tau_{t+1}^{c}\right)}\left\{(1-\delta)-\frac{\xi}{2}\left(\frac{k_{i, t+1}}{k_{i, t}}-1\right)^{2}+\xi\left(\frac{k_{i, t+1}}{k_{i, t}}-1\right) \frac{k_{i, t+1}}{k_{i, t}}+\left(1-\tau_{t+1}^{k}\right) r_{t+1}^{k}\right\} \\
& \chi_{m} \frac{\partial u_{i, t}}{\partial m_{i . t}}=\frac{\partial u_{i, t}}{\partial c_{i, t}} \frac{\partial c_{i, t}}{\partial c_{i, t}^{H}} \frac{P_{t}}{P_{t}^{H}\left(1+\tau_{t}^{c}\right)}-\beta E_{t} \frac{\partial u_{i, t+1}}{\partial c_{i, t+1}} \frac{\partial c_{i, t+1}}{\partial c_{i, t+1}^{H}} \frac{P_{t+1}}{P_{t+1}^{H}\left(1+\tau_{t+1}^{c}\right)} \frac{P_{t}}{P_{t+1}} \\
& -\chi_{n} \frac{\partial u_{i, t}}{\partial n_{i, t}}=\frac{\left(1-\tau_{t}^{n}\right)}{\left(1+\tau_{t}^{c}\right)} w_{t} \frac{\partial u_{i, t}}{\partial c_{i, t}} \frac{\partial c_{i, t}}{\partial c_{i, t}^{H}} \frac{P_{t}}{P_{t}^{H}} \\
& \frac{c_{i, t}^{H}}{c_{i, t}^{F}}=\frac{\nu}{1-\nu} \frac{P_{t}^{F}}{P_{t}^{H}} \\
& c_{i, t}^{H}(h)=\left[\frac{P_{t}^{H}(h)}{P_{t}^{H}}\right]^{-\phi} c_{i, t}^{H} \\
& c_{i, t}^{F}(f)=\left[\frac{P_{t}^{F}(f)}{P_{t}^{F}}\right]^{-\phi} c_{i, t}^{F}
\end{aligned}
$$

Equations (11)-(13) are respectively the Euler equations for domestic bonds, foreign assets and domestic capital, (14) is the optimality condition for money balances and (15) is the optimality condition for work hours. Finally, (16) shows the optimal allocation between domestic and foreign goods, while (17) and (18) show the optimal demand for each variety of domestic and foreign goods respectively.

\subsubsection{Implications for price bundles}

Equations (16), (17) and (18), combined with (4), (5) and (6), imply that the three price indexes are (see also e.g. Wickens, 2008, chapter 7):

$$
\begin{gathered}
P_{t}=\left(P_{t}^{H}\right)^{\nu}\left(P_{t}^{F}\right)^{1-\nu} \\
P_{t}^{H}=\left[\sum_{h=1}^{N} \lambda_{h}\left[P_{t}^{H}(h)\right]^{1-\phi}\right]^{\frac{1}{1-\phi}} \\
P_{t}^{F}=\left[\sum_{f=1}^{N} \lambda_{f}\left[P_{t}^{F}(f)\right]^{1-\phi}\right]^{\frac{1}{1-\phi}}
\end{gathered}
$$




\subsection{Firms}

There are $h=1,2, \ldots, . N$ domestic firms. Each firm $h$ produces a differentiated good of variety $h$ under monopolistic competition facing Calvo-type nominal fixities.

\subsubsection{Demand for firm's product}

Each domestic firm $h$ faces demand for its product, $y_{t}^{H}(h)$, coming from domestic households' consumption and investment, $c_{t}^{H}(h)$ and $x_{t}(h)$, where $c_{t}^{H}(h) \equiv \sum_{i=1}^{N} c_{i, t}^{H}(h)$ and $x_{t}(h) \equiv$ $\sum_{i=1}^{N} x_{i, t}(h)$, from the domestic government, $g_{t}(h)$, and from foreign households' consumption, $c_{t}^{F *}(h) \equiv \sum_{i=1}^{N *} c_{i, t}^{F *}(h)$. Thus, the demand for each domestic firm's product is:

$$
y_{t}^{H}(h)=c_{t}^{H}(h)+x_{t}(h)+g_{t}(h)+c_{t}^{F *}(h)
$$

where, as in (17-18), we have:

$$
\begin{gathered}
c_{t}^{H}(h)=\left[\frac{P_{t}^{H}(h)}{P_{t}^{H}}\right]^{-\phi} c_{t}^{H} \\
x_{t}(h)=\left[\frac{P_{t}^{H}(h)}{P_{t}^{H}}\right]^{-\phi} x_{t} \\
g_{t}(h)=\left[\frac{P_{t}^{H}(h)}{P_{t}^{H}}\right]^{-\phi} g_{t} \\
c_{t}^{F *}(h)=\left[\frac{P_{t}^{F *}(h)}{P_{t}^{F *}}\right]^{-\phi} c_{t}^{F *}
\end{gathered}
$$

where, using the law of one price discussed above, we have in (26):

$$
\frac{P_{t}^{F *}(h)}{P_{t}^{F *}}=\frac{\frac{P_{t}^{H}(h)}{S_{t}}}{\frac{P_{t}^{H}}{S_{t}}}=\frac{P_{t}^{H}(h)}{P_{t}^{H}}
$$

Since, at the economy level, agreggate demand for domestically produced goods is:

$$
y_{t}^{H}=c_{t}^{H}+x_{t}+g_{t}+c_{t}^{F *}
$$

the above equations imply that the demand for each domestic firm's product is:

$$
y_{t}^{H}(h)=c_{t}^{H}(h)+x_{t}(h)+g_{t}(h)+c_{t}^{F *}(h)=\left[\frac{P_{t}^{H}(h)}{P_{t}^{H}}\right]^{-\phi} y_{t}^{H}
$$




\subsubsection{Firm's problem}

Each firm $h$ maximizes nominal profits, $D_{t}(h)$, defined as:

$$
D_{t}(h)=P_{t}^{H}(h) y_{t}^{H}(h)-r_{t}^{k} P_{t}^{H}(h) k_{t-1}(h)-W_{t} n_{t}(h)
$$

All firms use the same technology represented by the production function:

$$
y_{t}^{H}(h)=A_{t}\left[k_{t-1}(h)\right]^{\alpha}\left[n_{t}(h)\right]^{1-\alpha}
$$

where $A_{t}$ is an exogenous stochastic TFP process whose motion is defined below.

Since the firm operates under imperfect competition, profit maximization is subject to the demand for its product:

$$
y_{t}^{H}(h)=\left[\frac{P_{t}^{H}(h)}{P_{t}^{H}}\right]^{-\phi} y_{t}^{H}
$$

In addition, following Calvo (1983), firms choose their prices facing a nominal fixity. In each period, firm $h$ faces an exogenous probability $\theta$ of not being able to reset its price. A firm $h$, which is able to reset its price, chooses its price $P_{t}^{\#}(h)$ to maximize the sum of discounted expected nominal profits for the next $k$ periods in which it may have to keep its price fixed.

\subsubsection{Firm's optimality conditions}

To solve the firm's problem above, we again follow a two-step procedure. We first solve a cost minimization problem, where each firm $h$ minimizes its cost by choosing factor inputs given technology and prices. The solution will give a minimum nominal cost function, which is a function of factor prices and output produced by the firm. In turn, given this cost function, each firm, which is able to reset its price, solves a maximization problem by choosing its price.

The solution to the cost minimization problem gives the input demand functions:

$$
\begin{aligned}
& w_{t}=m c_{t}(1-a) \frac{y_{t}(h)}{n_{t}(h)} \\
& \frac{P_{t}^{H}}{P_{t}} r_{t}^{k}=m c_{t} a \frac{y_{t}(h)}{k_{t-1}(h)}
\end{aligned}
$$

where $m c_{t}$ is real marginal cost. Also, $\Psi_{t}($.$) denotes the minimum nominal cost function for$ producing $y_{t}^{H}(h)$ at $t$ and $\Psi_{t}^{\prime}($.$) is the associated nominal marginal cost.$ 
Then, the firm chooses its price to maximize nominal profits written as:

$$
\max \sum_{k=0}^{\infty}(\theta)^{k} E_{t} \Xi_{t, t+k} D_{t+k}(h)=\sum_{k=0}^{\infty}(\theta)^{k} E_{t} \Xi_{t, t+k}\left\{P_{t}^{\#}(h) y_{t+k}^{H}(h)-\Psi_{t+k}\left(y_{t+k}^{H}(h)\right)\right\}
$$

where $\Xi_{t, t+k}$ is a discount factor taken as given by the firm and where $y_{t+k}^{H}(h)=\left[\frac{P_{t}^{\#}(h)}{P_{t+k}^{H}}\right]^{-\phi} y_{t+k}^{H}$. The first-order condition gives:

$$
\sum_{k=0}^{\infty}(\theta)^{k} E_{t} \Xi_{t, t+k}\left[\frac{P_{t}^{\#}(h)}{P_{t+k}^{H}}\right]^{-\phi} y_{t+k}^{H}\left\{P_{t}^{\#}(h)-\frac{\phi}{\phi-1} \Psi_{t+k}^{\prime}\right\}=0
$$

We transform the above equation by dividing by the domestic aggregate price index, $P_{t}^{H}$ :

$$
\sum_{k=0}^{\infty}(\theta)^{k} E_{t}\left[\Xi_{t, t+k}\left[\frac{P_{t}^{\#}(h)}{P_{t+k}^{H}}\right]^{-\phi} y_{t+k}^{H}\left\{\frac{P_{t}^{\#}(h)}{P_{t}^{H}}-\frac{\phi}{\phi-1} m c_{t+k} \frac{P_{t+k}}{P_{t}^{H}}\right\}\right]=0
$$

Therefore, the behaviour of each firm $h$ is summarized by the above three conditions, (33),

(34) and (36).

Each firm $h$ which can reset its price in period $t$ solves an identical problem, so $P_{t}^{\#}(h)=P_{t}^{\#}$ is independent of $h$, and each firm $h$ which cannot reset its price just set its previous period price $P_{t}^{H}(h)=P_{t-1}^{H}(h)$. Thus, the evolution of the aggregate price level is given by:

$$
\left(P_{t}^{H}\right)^{1-\phi}=\theta\left(P_{t-1}^{H}\right)^{1-\phi}+(1-\theta)\left(P_{t}^{\#}\right)^{1-\phi}
$$

\subsection{Government budget constraint}

The period budget constraint of the government expressed in real terms is (in aggregate quantities):

$$
\begin{gathered}
b_{t}+m_{t}+\frac{S_{t} P_{t}^{*}}{P_{t}} f_{t}^{g}=\frac{\phi^{g}}{2}\left(\frac{S_{t} P_{t}^{*}}{P_{t}} f_{t}^{g}-\frac{S P^{*}}{P} f^{g}\right)^{2}+R_{t-1} \frac{P_{t-1}}{P_{t}} b_{t-1}+\frac{P_{t-1}}{P_{t}} m_{t-1}+ \\
+Q_{t-1} \frac{S_{t} P_{t}^{*}}{P_{t}} \frac{P_{t-1}^{*}}{P_{t}^{*}} f_{t-1}^{g}+\frac{P_{t}^{H}}{P_{t}} g_{t}-\tau_{t}^{c}\left(\frac{P_{t}^{H}}{P_{t}} c_{t}^{H}+\frac{P_{t}^{F}}{P_{t}} c_{t}^{F}\right)-\tau_{t}^{k}\left(r_{t}^{k} \frac{P_{t}^{H}}{P_{t}} k_{t-1}+d_{t}\right)-\tau_{t}^{n} w_{t} n_{t}-\tau_{t}^{l}
\end{gathered}
$$

where $b_{t}$ is the end-of-period total domestic real public debt, $m_{t}$ is the end-of-period total stock of real money balances and $f_{t}^{g}$ is the end-of-period total external real public debt expressed in foreign prices. We also use $c_{t}^{H} \equiv \sum_{i=1}^{N} c_{i, t}^{H}, c_{t}^{F} \equiv \sum_{i=1}^{N} c_{i, t}^{F}, k_{t-1} \equiv \sum_{i=1}^{N} k_{i, t-1}, D_{t} \equiv \sum_{i=1}^{N} D_{i, t}$, $n_{t} \equiv \sum_{i=1}^{N} n_{i, t}, F_{t-1}^{h} \equiv \sum_{i=1}^{N} F_{i, t-1}^{h}, B_{t-1} \equiv \sum_{i=1}^{N} B_{i, t-1}$ and $T_{t}^{l} \equiv \sum_{i=1}^{N} T_{i, t}^{l}$. Notice that, as above, small letters denote real variables, namely, $b_{t} \equiv \frac{B_{t}}{P_{t}}, m_{t} \equiv \frac{M_{t}}{P_{t}}, f_{t}^{g} \equiv \frac{F_{t}^{g}}{P_{t}^{*}}, d_{t} \equiv \frac{D_{t}}{P_{t}}, w_{t} \equiv$ $\frac{W_{t}}{P_{t}}$ and $\tau_{t}^{l} \equiv \frac{T_{t}^{l}}{P_{t}}$. Also, recall that the government allocates its total expenditure among product 
varieties $h$ by solving an identical problem with household $i$, so that $g_{t}(h)=\left[\frac{P_{t}^{H}(h)}{P_{t}^{H}}\right]^{-\phi} g_{t}$. The parameter $\phi^{g} \geq 0$ captures transaction costs similar to those of the household.

In each period, one of the fiscal policy instruments $\left(\tau_{t}^{c}, \tau_{t}^{k}, \tau_{t}^{n}, g_{t}, \tau_{t}^{l}, b_{t}, f_{t}^{g}\right)$ has to follow residually to satisfy the government budget constraint (see below).

\subsection{Closing the model: the world interest rate}

As is well known, to get a well-defined solution, we need to depart from the benchmark small open economy model. Following e.g. Schmitt-Grohé and Uribe (2003), we do so by endogenizing the interest rate faced by the country when it borrows from the world capital markets, $Q_{t}$. We thus assume that $Q_{t}$ is an increasing function of total public debt as a share of output. Our assumption is supported by a number of empirical studies (see e.g. European Commission, 2011).

In particular, following e.g. Schmitt-Grohé and Uribe (2003) and Christiano et al. (2010), we use the functional form:

$$
Q_{t}=Q_{t}^{*}+\psi\left(e^{\left(\frac{B_{t}+S_{t} F_{t}^{g}}{P_{t}^{H} Y_{t}^{H}}-\bar{d}\right)}-1\right)
$$

where $Q_{t}^{*}$ is exogenously given, $\bar{d}$ is an exogenous threshold value above which the interest rate on government debt starts rising above $Q_{t}^{*}$ (see below) and the parameter $\psi$ measures the elasticity of the interest rate with respect to deviations of total public debt from its threshold value. This will generate deviations from uncovered interest parity (see below).

\subsection{Monetary and fiscal policy regimes}

Before we solve the model, we need to specify the exchange rate and the fiscal policy regimes. Concerning the exchange rate regime, since the model is applied to Italy since 2001, we choose to solve it under fixed exchange rates. This implies that the nominal exchange rate, $S_{t}$, is treated as a policy instrument, while we choose the domestic nominal interest rate, $R_{t}$, to become an endogenous variable (see Appendix 1 for details). ${ }^{5}$ To understand what this implies,

\footnotetext{
${ }^{5}$ As we explain in more detail in Appendix 1, the fact that $S_{t}$ is exogenous does not necessarily imply that $R_{t}$ should become an endogenous variable. Some other policy instrument could play the role of the adjusting policy instrument, so that both $S_{t}$ and $R_{t}$ could be treated as policy instruments. We have experimented with several canidates in our numerical solutions below and we can report that, only when we treat $R_{t}$ as endogenous, the model gives well-defined solutions under fixed exchange rates. Recall that in the popular case of flexible, or managed floating, exchange rates, $S_{t}$ and $R_{t}$ switch positions, in the sense that $S_{t}$ becomes endogenous, while $R_{t}$ is used as a policy instrument usually assumed to follow a Taylor-type rule. For the modeling of different exchange rate regimes in similar models, see e.g. Gali and Monacelli (2005), Dellas and Tavlas (2005) and Collard and Dellas (2006).
} 
it is better to think in terms of certainty. Then, as can be seen from the arbitrage interest rate condition, $R_{t}$ is determined by the world interest rate, $Q_{t}^{*}$, which is exogenously given to the country, and the country's risk premium, which depends on endogenous variables. ${ }^{6}$ In other words, under fixed exchange rates, a semi-small country loses monetary policy independence. We believe this is a reasonable description of a small economy participating in the euro. Concerning fiscal policy, we start by assuming that the residually determined public financing policy instrument is the end-of-period government foreign debt, $F_{t}^{g}$ (see below for other cases).

\subsection{Decentralized equilibrium (given policy)}

We now combine the above to present the Decentralized Equilibrium (DE) for any feasible policy. The DE is defined to be a sequence of allocations, prices and policies such that: (i) households maximize utility; (ii) a fraction $(1-\theta)$ of firms maximize profits by choosing an identical price $P_{t}^{\#}$, while a fraction $\theta$ just set their previous period prices; (iii) all constraints, including the government budget constraint and the balance of payments, are satisfied; (iv) markets clear.

The DE is summarized by a dynamic system of 22 equations (see Appendix 2 for equations and details). Under the assumed monetary and fiscal policy regime, the 22 endogenous variables are $\left\{y_{t}^{H}, c_{t}, c_{t}^{H}, c_{t}^{F}, n_{t}, x_{t}, k_{t}, f_{t}^{h}, m_{t}, P_{t}^{F}, P_{t}, P_{t}^{H}, P_{t}^{\#}, \widetilde{P}_{t}^{H}, w_{t}, m c_{t}, d_{t}, r_{t}^{k}, Q_{t}, f_{t}^{g}, P_{t}^{*}, R_{t}\right\}_{t=0}^{\infty}$. This is given technology, $\left\{A_{t}\right\}_{t=0}^{\infty}$, the independently set monetary and fiscal policy instruments, $\left\{S_{t}, \tau_{t}^{c}, \tau_{t}^{k}, \tau_{t}^{n}, g_{t}, \tau_{t}^{l}, b_{t}\right\}_{t=0}^{\infty}$, the rest-of-the-world variables, $\left\{Q_{t}^{*}, P_{t}^{H *}, c_{t}^{F *}\right\}_{t=0}^{\infty}$, and initial conditions for the state variables. Before we specify the processes of policy instruments and exogenous variables, we transform the above equilibrium conditions.

\subsection{Decentralized equilibrium transformed (given policy)}

In this section, following the related literature, we rewrite the above equilibrium conditions, first, by expressing price levels in inflation rates, secondly, by writing the firm's optimality conditions in recursive form and, thirdly, by introducing a new equation that helps us to compute expected discounted lifetime utility. ${ }^{7}$

\footnotetext{
${ }^{6}$ To see this, combine equations (11) and (12) under certainty. They imply $R_{t}=Q_{t} \frac{S_{t+1}}{S_{t}}$, which is the uncovered interest parity condition. Under fixed exchange rates, we simply have $R_{t}=Q_{t}$, where $Q_{t}$ consists of the exogenous rest-of-the world interest rate and the endogenous sovereign premium. See also e.g. Himmels and Kirsanova (2009) in a similar specification.

${ }^{7} \mathrm{~A}$ technical appendix to this section is available upon request.
} 


\subsubsection{Variables expressed in ratios}

We first express prices in rate form. We define 7 new endogenous variables, which are the gross domestic CPI inflation rate $\Pi_{t} \equiv \frac{P_{t}}{P_{t-1}}$, the gross foreign CPI inflation rate $\Pi_{t}^{*} \equiv \frac{P_{t}^{*}}{P_{t-1}^{*}}$, the gross domestic goods inflation rate $\Pi_{t}^{H} \equiv \frac{P_{t}^{H}}{P_{t-1}^{H}}$, the auxiliary variable $\Theta_{t} \equiv \frac{P_{t}^{\#}}{P_{t}^{H}}$, the price dispersion index $\Delta_{t} \equiv\left[\frac{\widetilde{P}_{t}^{H}}{P_{t}^{H}}\right]^{-\phi}$, the gross exchange rate depreciation rate $\epsilon_{t} \equiv \frac{S_{t}}{S_{t-1}}$ and the terms of trade $T T_{t} \equiv \frac{P_{t}^{F}}{P_{t}^{H}}=\frac{S_{t} P_{t}^{* H}}{P_{t}^{H}} .8$

We also find it convenient to denote $f_{t}^{T T} \equiv T T_{t}^{\nu^{*}} f_{t}^{g}$ and then use $f_{t}^{T T}$ as the residually determined fiscal policy instrument instead of $f_{t}^{g}$ itself. Thus, $f_{t}^{T T}$ denotes the government debt issued in foreign currency and expressed in domestic currency in real terms. Also, for convenience and following usual practice, we express the two exogenous fiscal policy instruments as ratios of GDP, $s_{t}^{g} \equiv \frac{g_{t}}{y_{t}^{H}}$ and $s_{t}^{l} \equiv \frac{\tau^{l}}{y_{t}^{H}}$.

Thus, in what follows, we use $\Pi_{t}, \Pi_{t}^{*}, \Pi_{t}^{H}, \Theta_{t}, \Delta_{t}, \epsilon_{t}, T T_{t}, f_{t}^{T T}, s_{t}^{g}, s_{t}^{l}$ instead of $P_{t}, P_{t}^{*}$, $P_{t}^{H}, P_{t}^{\#}, \widetilde{P}_{t}, S_{t}, P_{t}^{F}, f_{t}^{g}, g_{t}, \tau_{t}^{l}$ respectively.

\subsubsection{Equation (36) expressed in recursive form}

Following Schmitt-Grohé and Uribe (2007), we seek for a recursive representation of equation (36):

$$
\sum_{k=0}^{\infty}(\theta)^{k} E_{t} \Xi_{t, t+k}\left[\frac{P_{t}^{\#}}{P_{t+k}^{H}}\right]^{-\phi} y_{t+k}^{H}\left\{P_{t}^{\#}-\frac{\phi}{(\phi-1)} m c_{t+k} P_{t+k}\right\}=0
$$

We define two auxiliary endogenous variables:

$$
\begin{gathered}
z_{t}^{1} \equiv \sum_{k=0}^{\infty}(\theta)^{k} E_{t} \Xi_{t, t+k}\left[\frac{P_{t}^{\#}}{P_{t+k}^{H}}\right]^{-\phi} y_{t+k}^{H} \frac{P_{t}^{\#}}{P_{t}} \\
z_{t}^{2} \equiv \sum_{k=0}^{\infty}(\theta)^{k} E_{t} \Xi_{t, t+k}\left[\frac{P_{t}^{\#}}{P_{t+k}^{H}}\right]^{-\phi} y_{t+k}^{H} m c_{t+k} \frac{P_{t+k}}{P_{t}}
\end{gathered}
$$

Using these two auxiliary variables, $z_{t}^{1}, z_{t}^{2}$, and equation (40), we come up with two new equations which enter the dynamic system and allows a recursive representation of (40).

${ }^{8}$ Thus, $\frac{T T_{t}}{T T_{t-1}}=\frac{\frac{S_{t}}{S_{t-1}} \frac{P_{t}^{* H}}{P_{t-1}^{* H}}}{\frac{P_{t}^{H}}{P_{t-1}^{H}}}=\frac{\epsilon_{t} \Pi_{t}^{* H}}{\Pi_{t}^{H}}$. 
Thus, in what follows, we replace equation (66) with its recursive representation:

$$
z_{t}^{1}=\frac{\phi}{(\phi-1)} z_{t}^{2}
$$

where:

$$
\begin{gathered}
z_{t}^{1}=\Theta_{t}^{1-\phi} y_{t} T T_{t}^{\nu-1}+\beta \theta E_{t} \frac{c_{t+1}^{-\sigma}}{c_{t}^{-\sigma}} \frac{1+\tau_{t}^{c}}{1+\tau_{t+1}^{c}}\left(\frac{\Theta_{t}}{\Theta_{t+1}}\right)^{1-\phi}\left(\frac{1}{\Pi_{t+1}^{H}}\right)^{1-\phi} z_{t+1}^{1} \\
z_{t}^{2}=\Theta_{t}^{-\phi} y_{t} m c_{t}+\beta \theta E_{t} \frac{c_{t+1}^{-\sigma}}{c_{t}^{-\sigma}} \frac{1+\tau_{t}^{c}}{1+\tau_{t+1}^{c}}\left(\frac{\Theta_{t}}{\Theta_{t+1}}\right)^{-\phi}\left(\frac{1}{\Pi_{t+1}^{H}}\right)^{-\phi} z_{t+1}^{2}
\end{gathered}
$$

\subsubsection{Lifetime utility written as a first-order dynamic equation}

Since we want to compute social welfare, we follow Schmitt-Grohé and Uribe (2007) by defining a new endogenous variable, $V_{t}$, whose motion is given by:

$$
V_{t}=\frac{c_{t}^{1-\sigma}}{1-\sigma}-\chi_{n} \frac{n_{t}^{1+\phi}}{1+\phi}+\chi_{m} \frac{m_{t}^{1-\mu}}{1-\mu}+\chi_{g} \frac{\left(s_{t}^{g} y_{t}^{H}\right)^{1-\zeta}}{1-\zeta}+\beta E_{t} V_{t+1}
$$

where $V_{t}$ is household's expected discounted lifetime utility at time $t$.

Thus, in what follows, we add equation (46) and the new variable $V_{t}$ to the equilibrium system.

\subsubsection{Equilirium conditions rewritten}

Using the above, the transformed DE is summarized by a dynamic system of 25 equations (see Appendix 3 for equations and details). The 25 endogenous variables are $\left\{V_{t}, y_{t}^{H}, c_{t}, c_{t}^{H}, c_{t}^{F}\right.$, $\left.n_{t}, x_{t}, k_{t}, f_{t}^{h}, m_{t}, T T_{t}, \Pi_{t}, \Pi_{t}^{H}, \Theta_{t}, \Delta_{t}, w_{t}, m c_{t}, d_{t}, r_{t}^{k}, Q_{t}, f_{t}^{T T}, \Pi_{t}^{*}, z_{t}^{1}, z_{t}^{2}, R_{t}\right\}_{t=0}^{\infty}$. This is given technology, $\left\{A_{t}\right\}_{t=0}^{\infty}$, the independently set policy instruments, $\left\{\epsilon_{t} \equiv 1, \tau_{t}^{c}, \tau_{t}^{k}, \tau_{t}^{n}, s_{t}^{g}, s_{t}^{l}\right.$, $\left.b_{t}\right\}_{t=0}^{\infty}$, the rest-of-the-world variables, $\left\{Q_{t}^{*}, \Pi_{t}^{H *}, c_{t}^{F *}\right\}_{t=0}^{\infty}$, and initial conditions for the state variables. We next specify the fiscal policy instruments and exogenous variables.

\section{$2.9 \quad$ Fiscal policy rules}

Without room for monetary policy independence, only fiscal policy can be used for stabilization. Following Schmitt-Grohé and Uribe (2007) and many others, we focus on simple rules meaning that the fiscal authorities react to a small number of easily observable macroeconomic indicators. In particular, we allow the non-lump sum spending-tax policy instruments, $s_{t}^{g}, \tau_{t}^{c}$, $\tau_{t}^{k}, \tau_{t}^{n}$, to react to the public debt-to-output ratio as deviation from a target, as well as to the 
output gap, according to the linear rules (for similar rules, see e.g Schmitt-Grohé and Uribe (2007), Bi (2010) and Cantore et al. (2012)):

$$
\begin{gathered}
s_{t}^{g}-s^{g}=-\gamma_{l}^{g}\left(l_{t-1}-l\right)-\gamma_{y}^{g}\left(y_{t}^{H}-y^{H}\right) \\
\tau_{t}^{c}-\tau^{c}=\gamma_{l}^{c}\left(l_{t-1}-l\right)+\gamma_{y}^{c}\left(y_{t}^{H}-y^{H}\right) \\
\tau_{t}^{k}-\tau^{k}=\gamma_{l}^{k}\left(l_{t-1}-l\right)+\gamma_{y}^{k}\left(y_{t}^{H}-y^{H}\right) \\
\tau_{t}^{n}-\tau^{n}=\gamma_{l}^{n}\left(l_{t-1}-l\right)+\gamma_{y}^{n}\left(y_{t}^{H}-y^{H}\right)
\end{gathered}
$$

where variables without time subscripts denote long-run values, $\gamma_{l}^{q} \geq 0$ and $\gamma_{y}^{q} \geq 0$ are feedback fiscal policy coefficients on inherited public liabilities, and output, $y_{t}^{H}$, respectively, as deviations from their long-run values, and where $q \equiv\left(s^{g}, \tau^{c}, \tau^{k}, \tau^{n}\right)$. Inherited public liabilities are denoted as:

$$
l_{t}=\frac{R_{t} \frac{1}{\Pi_{t+1}} b_{t}+Q_{t} T T_{t+1}^{v+v^{*}-1} \frac{1}{\Pi_{t+1}^{*}} \frac{f_{t}^{T T}}{T T_{t}^{\nu^{*}}}}{y_{t}^{H}}
$$

\subsection{Exogenous variables and productivity shocks}

We assume that, along the transition, foreign imports are a function of terms of trade, where both variables are expressed as deviations from their long-run values:

$$
\frac{c_{t}^{F *}}{c^{F *}}=\left(\frac{T T_{t}}{T T}\right)^{\gamma}
$$

where $0<\gamma<1$ is a parameter. The idea is that foreign imports, or equivalently domestic exports, rise when the domestic economy becomes more competitive. Regarding the other rest-of-the-world variables, $Q_{t}^{*}, \Pi_{t}^{H *}$, we simply assume that they are constant over time and equal to $Q_{t}^{*}=1.0303$ (which is as in the data - see below) and $\Pi_{t}^{H *}=1$.

We also assume that the TFP follows a stochastic AR(1) process:

$$
\log \left(A_{t}\right)=\left(1-\rho^{a}\right) \log (A)+\rho^{a} \log \left(A_{t-1}\right)+\varepsilon_{t}^{\alpha}
$$

where $0<\rho<1$ is a parameter, variables without time subscript denote long-run values and $\varepsilon_{t}^{a} \sim N\left(0, \sigma_{a}^{2}\right)$ 


\subsection{Final equlibrium system (given feedback policy coefficients)}

We now present the final equilibrium system. It consists of the 25 equations of the transformed DE as defined in subsection 2.8.4, the 5 equations for the policy instruments in subsection 2.9, and the equation for exports in subsection 2.10. Thus, we have a system of 31 equations. This is a second-order system. By using 2 auxilliary variables, we can me make it a first-order, ${ }^{9}$ so we end up with 33 equations in 33 variables, $\left\{y^{H}, c, c^{H}, c^{F}, x, n, m, f^{h}, f^{T T}, k, d, m c, \Pi, \Pi^{H}\right.$, $\left.\Pi^{*}, \Theta, \Delta, T T, w, r^{k}, Q, l, z^{1}, z^{2}, V ; R, \tau^{c}, s^{g}, \tau^{k}, \tau^{n} ; k l e a d, T T l a g, c^{F *}\right\}$. This is given the exogenous variables, $\left\{Q_{t}^{*}, \Pi_{t}^{H *}, A_{t}\right\}_{t=0}^{\infty}$. The classification of endogenous variables into control and state variables is 25 control variables, $\left\{y_{t}^{H}, c_{t}, c_{t}^{H}, c_{t}^{F}, x_{t}, n_{t}, d_{t}, m c_{t}, \Pi_{t}, \Pi_{t}^{H}, \Pi_{t}^{*}, \Theta_{t}\right.$, $T T_{t}, w_{t}, r_{t}^{k}, l_{t}, z_{t}^{1}, z_{t}^{2}, V_{t}$, klead $\left._{t}, c_{t}^{F *}, \tau_{t}^{c}, s_{t}^{g}, \tau_{t}^{k}, \tau_{t}^{n}\right\}$, and 8 state variables, $\left\{m_{t-1}, f_{t-1}^{h}, f_{t-1}^{T T}\right.$, $\left.k_{t-1}, \Delta_{t-1}, Q_{t-1}, R_{t-1}, T T \operatorname{Tlag}_{t}\right\}$. All this is given the values of feedback policy coefficients as defined in subsection 2.9 .

To solve this system, we take a second-order approximation around its long-run solution. We start with the long-run solution in the next section 3. In turn, we will study transition dynamics and the optimal choice of feedback policy coefficients.

\section{Data, calibration and long-run solution}

This section calibrates the model to fiscal and public finance data from Italy over 2001-2011 and then presents the long-run solution. Recall that, since money is neutral in the long-run, the exchange rate regime does not matter to the real economy. Similarly, since policy instruments react to deviations of macroeconomic indicators from their long-run values, feedback fiscal policy coefficients also do not play any role in the long run solution.

\subsection{Data and calibration}

The fiscal and public finance data for Italy are from OECD Statistics and the Eurostat. Regarding parameters, we use conventional values used by related New Keynesian papers on the euro area. The time unit is meant to be a year. The baseline parameter values are summarized in Table 1.

\footnotetext{
${ }^{9}$ In particular, we add 2 auxiliary endogenous variables, klead and TTlag, to reduce the dynamic system into a first-order one.
} 
Table 1: Baseline parameter values

\begin{tabular}{lll}
\hline \hline Parameter & Value & Description \\
\hline \hline$a$ & 0.42 & share of capital \\
\hline$\beta$ & 0.9603 & time preference rate \\
\hline$\nu$ & $\frac{1}{2}$ & home goods bias parameter \\
\hline$\mu$ & 3.42 & parameter related to money demand elasticity \\
\hline$\delta$ & 0.04 & capital depreciation rate \\
\hline$\phi$ & 6 & price elasticity of demand \\
\hline$\eta$ & 1 & Frisch labour elasticity \\
\hline$\sigma$ & 1 & elasticity of intertemporal substitution \\
\hline$\nu^{*}$ & $\frac{1}{2}$ & foreign goods bias parameter \\
\hline$\theta$ & 0.5 & price rigidity parameter \\
\hline$\psi$ & 0.05 & risk premia parameter \\
\hline$\chi_{m}$ & 0.001 & preference parameter related to real money balances \\
\hline$\chi_{n}$ & 7 & preference parameter related to work effort \\
\hline$\chi_{g}$ & 0.1 & preference parameter related to public spending \\
\hline $\bar{d}$ & 0.9 & threshold value for public debt \\
\hline$\rho^{a}$ & 0.92 & persistence of TFP \\
\hline$\sigma_{a}$ & 0.017 & standard deviation of TFP \\
\hline$\gamma$ & 0.9 & foreign imports parameter \\
\hline$\xi$ & 2 & adjustment cost parameter on physical capital \\
\hline$\phi^{g}$ & 2 & adjustment cost parameter on foreign public debt \\
\hline \hline
\end{tabular}

The value of the time preference rate, $\beta$, follows from setting $R=1.0413$ for the gross nominal interest rate (this implies a risk premium of 1.1\% over the German 10-year bond rate, which is the average value in the data) and from $\Pi=1$ for the long-run gross inflation rate. The real money balances elasticity, $\mu$, is taken from Pappa and Neiss (2005). We use standard values used by the literature for the elasticity of intertemporal substitution, $\sigma$, the Frisch labour elasticity, $\eta$, and the price elasticity of demand, $\phi$, which are all taken from Andrès and Doménech (2006) and Gali (2008). Regarding preference parameters in the utility function, $\chi_{m}$ is chosen to obtain a yearly steady-state value for real money balances as ratio of output $0.48, \chi_{n}$ is chosen to obtain yearly steady-state labour hours 0.27 , while $\chi_{g}$ is set at 0.1 . 
In our baseline parameterization, the critical value of the output share of public debt above which sovereign risk premia emerge, $\bar{d}$, is set at 0.9 , which is consistent with the evidence provided by Reinhart and Rogoff (2010) that, in advanced economies, there is no obvious link between public debt and macroeconomic performance until total public debt reaches the $90 \%$ threshold. The associated risk premium parameter, $\psi$, is set at 0.05 , which, jointly with the value of $\bar{d}$, implies a steady-state risk premium for Italy over the German rate equal to $1.1 \%$. These values are in line with empirical findings for OECD countries (see Ardagna et al., 2004). This parameterization means that, when public debt increases by 1 percentage point from its threshold value $\bar{d}$, the nominal interest rate paid by the country increases by 5 basis points above its steady-state value. We report that our main results are robust to changes in these parameter values.

Concerning the exogenous stochastic variables, we set $\rho^{a}=0.92$ and $\sigma_{a}=0.017$ for persistence and standard deviation respectively of the TFP shock (the value of $\rho^{a}$ is similar to that in Schmitt-Grohé and Uribe, 2007, while the value of $\sigma_{a}$ is close to that in $\mathrm{Bi}, 2010$, and Bi and Kumhof, 2009). As reported below, our results are robust to changes in these values. Regarding the rest-of-the world variables, $\Pi_{t}^{H *}, Q_{t}^{*}$ and $c_{t}^{F *}$, we set their long run values equal to, $\Pi^{H *}=1, Q^{*}=1.0303$ and $c^{F *}=0.9 c^{F}$, where 0.9 is calibrated to replicate the net export position found in the Italian data. The parameter $\gamma$ in equation (52) for foreign imports is set at 0.9 ; in combination with the other parameters, this gives a dynamically stable solution.

The long-run values of the exogenous policy instruments, $\tau_{t}^{c}, \tau_{t}^{k}, \tau_{t}^{n}, s_{t}^{g}, s_{t}^{l}, b_{t}$, are either set at their data averages, or are calibrated to deliver data-consistent steady-state values for the residually determined fiscal variables. In particular, $\tau^{c}, \tau^{k}, \tau^{n}$ are the effective tax rates in the data over 2001-2011. We set $s^{l}$ so as to obtain the sum $-s^{l}+s^{g}$ close to 0.45 , which is consistent with the Italian data, while $s^{b} \equiv \frac{b}{y^{H}}$, namely, the domestic public debt-to-output ratio is also set at its average value in the Italian data. The long-run values of policy variables are summarized in Table 2. 
Table 2: Average values of policy instruments

\begin{tabular}{ccccccc}
\hline \hline$R$ & $\tau^{c}$ & $\tau^{k}$ & $\tau^{n}$ & $s^{g}$ & $s^{l} \equiv \frac{\tau^{l}}{y^{H}}$ & $s^{b}$ \\
\hline \hline 1.0413 & 0.17 & 0.32 & 0.42 & 0.22 & -0.23 & 0.715 \\
\hline \hline
\end{tabular}

\subsection{Long-run solution (the "status quo")}

Table 3 presents the long-run solution of the model economy when we use the parameter values in Table 1 and the policy instruments in Table 2. We also present some key ratios in the Italian data whenever available. Most of the solved ratios are close to their actual values. Notice that our solution for total foreign debt as share of output is $\frac{f^{T T}-T T^{\nu^{*}} f^{h}}{y^{H}}=0.44$; its value in the data is around 0.35 (see Diz Dias, 2010, for external debt statistics of the euro area).

This solution will serve as a point of departure. That is, in what follows, we depart from this solution to study various policy experiments. This is why we call it the "status quo" solution.

Table 3: Long-run solution (the "status quo")

\begin{tabular}{|c|c|c|c|c|}
\hline \hline Variables & $\begin{array}{c}\text { Long-run } \\
\text { values }\end{array}$ & Variables & $\begin{array}{c}\text { Long-run } \\
\text { values }\end{array}$ & Data \\
\hline \hline$y^{H}$ & 0.59 & $V$ & 16.3205 & - \\
$c$ & 0.42 & $\Pi^{*}$ & 1 & \\
$c^{H}$ & 0.19 & $z^{1}$ & 1.24 & - \\
$c^{F}$ & 0.22 & $z^{2}$ & 1.033 & - \\
$n$ & 0.27 & $l$ & 1.24 & - \\
$x$ & 0.07 & $\frac{c}{y^{H}}$ & 0.7 & 0.73 \\
$f^{h}$ & 0.001 & $\frac{k}{y^{H}}$ & 2.93 & 3.48 \\
$m$ & 0.28 & $T T^{\nu^{*}} \frac{f^{h}}{y^{H}}$ & 0.0015 & 0.1 \\
$T T$ & 0.85 & $\frac{m}{y^{H}}$ & 0.48 & - \\
$w$ & 1.14 & $\frac{f^{T T}}{y^{H}}$ & 0.44 & 0.42 \\
$m c$ & 0.9 & $\frac{f^{T T}-T T^{\nu^{*}} f^{h}}{y^{H}}$ & 0.44 & 0.35 \\
$d^{H}$ & 0.11 & $\Pi$ & 1 & - \\
$r^{k}$ & 0.12 & $\Pi^{H}$ & 1 & - \\
$Q$ & 1.0413 & $\Theta$ & 1 & - \\
$k$ & 1.74 & $\Delta$ & 1 & - \\
\hline \hline
\end{tabular}




\section{How we work to study policy}

We now study the implications of different policy rules for macroeconomic outcomes and social welfare. To make the comparison of different policies meaningful, we compare optimal policies and, in particular, optimized policy rules, so that results do not depend on ad hoc differences in policies compared. The welfare criterion is household's expected lifetime utility.

Recall that, along the transition path, nominal rigidities imply that money is not neutral so that monetary policy and the exchange rate regime matter to the real economy. As said, here we focus on fixed exchange rates and loss of monetary policy independence. Also, recall that, along the transition path, different counter-cyclical fiscal policy rules can have different implications. That is, we will welfare rank different counter-cyclical fiscal policy rules when there is no room for monetary policy.

\subsection{The role of policy in our model}

We will study two environments regarding policy. In the first (see section 5 ), the role of policy is to stabilize the economy against temporary TFP shocks as defined in equation (53) above. In the second environment (see section 6), the role of policy is twofold: to stabilize the economy against shocks and, at the same time, to improve resource allocation by gradually reducing the public debt ratio over time. Although the second environment is richer, the first one helps us to understand how the model works and serves as a benchmark.

Irrespectively of the role of policy, we need to compute optimized policy rules. This is explained in the rest of this section.

\subsection{How we compute optimized policy rules and the resulting equilibrium}

We work in two steps. In the first preliminary step, we search for the ranges of feedback policy coefficients, as defined in (47-50), which allow us to get a locally determinate equilibrium (this is what Schmitt-Grohé and Uribe, 2007, call implementable rules). If necessary, these ranges will be further restricted so as to give economically meaningful solutions for the policy instruments (e.g. tax rates less than one). In our search for local determinacy, we experiment with one, or more, policy instruments and one, or more, operating targets at a time.

In the second step, within the determinacy ranges found above, we compute the welfaremaximizing values of feedback policy coefficients (this is what Schmitt-Grohé and Uribe, 2005 and 2007, call optimized policy rules). The welfare criterion is to maximize the conditional wel-

fare, $V_{0}$, as defined in (46) above, where conditionality refers to the initial conditions chosen; the latter are given by the status quo long-run solution. To this end, following e.g. Schmitt-Grohé 
and Uribe (2004), we take a second-order approximation to both the equilibrium conditions and the welfare criterion. As is well known, this is consistent with risk-averse behavior on the part of economic agents and can also help us to avoid possible spurious welfare results that may arise when one takes a second-order approximation to the welfare criterion combined with a first-order approximation to the equilibrium conditions (see e.g. Gali, 2008, pp. 110-111, Malley et al., 2009, and, for a recent review, Benigno and Woodford, 2012).

In other words, we compute the feedback policy coefficients so as to maximize the secondorder approximation of conditional welfare subject to the second-order appoximation of the decentralized equilibrium when the feedback policy coefficients are restricted to be within prespecified ranges delivering determinacy.

\section{$5 \quad$ Stabilization policy}

We now study the implications of different policy rules (see subsection 2.9) when the role of policy is to stabilize the economy from shocks (see subsection 2.10). This is a pure stabilization problem. Technically, this means that we depart from, and end up, at the same steady state as that found in section 3 above, so that transition dynamics are driven by shocks only.

In what follows, we assume that the economy is hit by an adverse temporary shock to TFP. The latter causes a recession and an increase in the public debt ratio and hence the sovereign risk premium.

\subsection{Optimized policy rules}

We first check local determinacy. We report that economic policy guarantees determinacy when fiscal policy instruments, $q_{t} \equiv\left(s_{t}^{g}, \tau_{t}^{c}, \tau_{t}^{k}, \tau_{t}^{n}\right)$, react to public liabilities above a critical minimum value $\gamma_{l}^{q}>\underline{\gamma}_{l}^{q}>0$. By contrast, the values of $\gamma_{y}^{q}$, measuring the reaction of fiscal policy to the output gap, are not found to be critical to determinacy. Details are available upon request, while the determinacy areas are shown in Appendix 4.

Within the determinacy areas found, we next turn to optimized policy rules. Thus, as explained above, we search for those values of the feedback policy coefficients, and the indicators that the policy instruments respond to, that maximize household's conditional welfare as defined in equation (46). Following the tradition, we start by allowing fiscal policy to react to public liabilities and output. To understand what drives our results, and following usual practice, we examine one fiscal instrument at a time.

Results are reported in Table 4. The first colunm lists the fiscal policy instrument used, while the optimal reaction of each instrument to debt and output are in the second column. 
The third column reports the standard deviation of the instrument used, as well as its minimum value if the instrument is the public spending share, or its maximum value if it is a tax rate (we include this information because we want to make sure that we get values that make sense economically and also do not differ substantially from those in the historical data). The resulting expected discounted lifetime utility, $E_{0} V_{0}$, is reported in the last column. We also report that, in all solutions below, the equilibrium nominal interest rate does not violate its zero bound.

Table 4: Stabilization policy without monetary independence

\begin{tabular}{cccc}
\hline \hline $\begin{array}{c}\text { Fiscal } \\
\text { instrument }\end{array}$ & $\begin{array}{c}\text { Optimal reaction } \\
\text { to debt and output }\end{array}$ & $\begin{array}{c}\text { Volatility and } \\
\text { max/min value of } \\
\text { instruments }\end{array}$ & $E_{0} V_{0}$ \\
\hline \hline \multirow{2}{*}{$s_{t}^{g}$} & $\gamma_{l}^{g}=0.21$ & std $=0.065$ & 16.3114 \\
& $\gamma_{y}^{g}=0.19$ & $s_{t}^{g}=0.217$ & \\
\hline \hline \multirow{2}{*}{$\tau_{t}^{c}$} & $\gamma_{l}^{c}=0.43$ & $s t d=0.14$ & \multirow{2}{*}{16.3123} \\
& $\gamma_{y}^{c}=0.57$ & $\tau_{t}^{c}=0.165$ & \\
\hline \hline \multirow{2}{*}{$\tau_{t}^{k}$} & $\gamma_{l}^{k}=0.8$ & $s t d=0.1404$ & \multirow{2}{*}{16.3146} \\
& $\gamma_{y}^{k}=1.2$ & $\tau_{t}^{k}=0.309$ & \\
\hline \hline & $\gamma_{t}^{n}=0.69$ & $s t d=0.09$ & 16.3119 \\
& $\gamma_{y}^{n}=0.96$ & $\tau_{t}^{n}=0.413$ & \\
\hline \hline
\end{tabular}

The results indicate that, to the extent that feedback policy coefficients are chosen optimally and the policy concern is shock stabilization only, the welfare differences among different fiscal policy instruments are unimportant (differences are at third decimal point only). Hence, at this early stage, we cannot draw any conclusions. Neverthless, given the robustness of our results (see below), it is worth pointing out the following. At first sight, it may look surprising that the best, or the least distorting, fiscal instrument is not public spending. This is what one should expect from related closed economy studies (see e.g. Philippopoulos et al., 2012) and from policy reports (see e.g. European Commission, 2011). However, recall that here we have a small open economy with sovereign risk premia. Sovereign risk premia introduce extra distortions/wedges in relative prices and thus tax rates are more suitable (than public spending) to offset these distortions/wedges (see also the discussion in Wren-Lewis, 2010). It is also worth pointing out that it is optimal to react to output in all cases shown in Table 4. Thus, fiscal activism appears to be productive. This is in contrast to the conventional wisdom 
that "counter-cyclical fiscal policy is counter-productive" (see e.g. Gordon and Leeper, 2003, Taylor, 2009, and Feldstein, 2009).

\subsection{Impulse response functions under optimized policy rules}

We now present the impulse responce functions (IRFs) of some key endogenous variables when there is a negative TFP shock (with a standard deviation of 0.017). Since, in all cases, it is optimal for policy instruments to react to more than one indicator at the same time, the IRFs are useful to illustrate which reaction dominates and what drives the change in the policy instrument over time.

Figure 1a starts with the case in which we use the share of public spending, $s_{t}^{g}$, as the state-contingent instrument. That is, following Table 4 , row $1, s_{t}^{g}$ reacts to public debt and output with feedback coefficients $\gamma_{l}^{g}=0.21$ and $\gamma_{y}^{g}=0.19$ respectively, while all other policy feedback coefficients are set at zero meaning that the other policy instruments, $\tau_{t}^{c}, \tau_{t}^{k}$ and $\tau_{t}^{n}$, remain constant at their steady-state values (data averages). Figures $1 \mathrm{~b}, 1 \mathrm{c}$ and $1 \mathrm{~d}$ do the same when we use $\tau_{t}^{c}, \tau_{t}^{k}$ and $\tau_{t}^{n}$ respectively as state-contingent policy instruments. Variables are expressed as log-deviations from their long-run values.

Figure 1a: IRFs to a negative TFP shock when the fiscal instrument is government spending
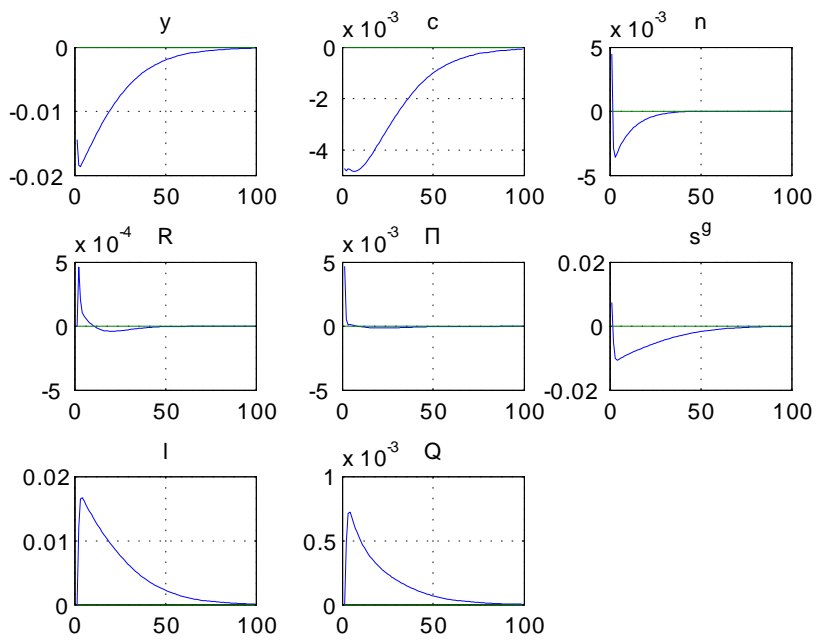
Figure 1b: IRFs to a negative TFP shock

when the fiscal instrument is the consumption tax rate
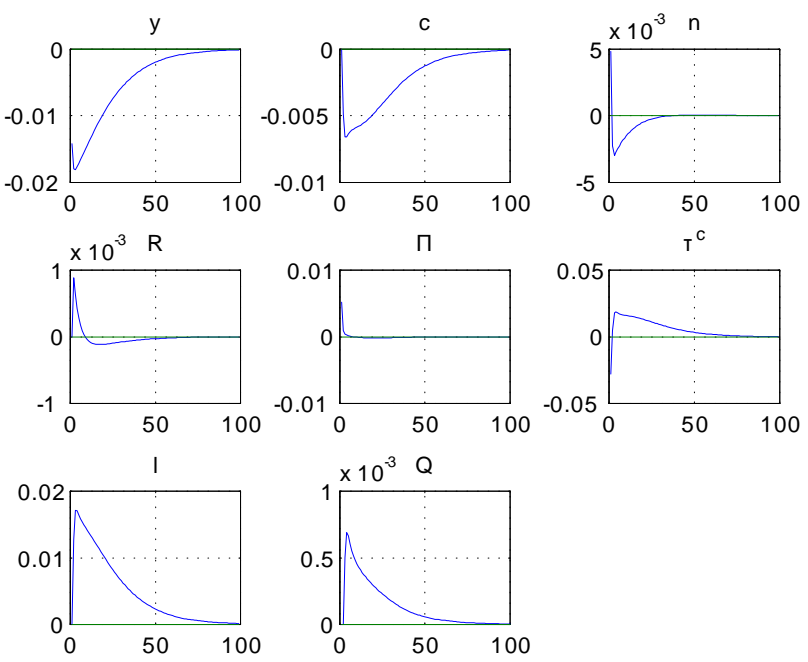

Figure 1c: IRFs to a negative TFP shock

when the fiscal instrument is the capital tax rate
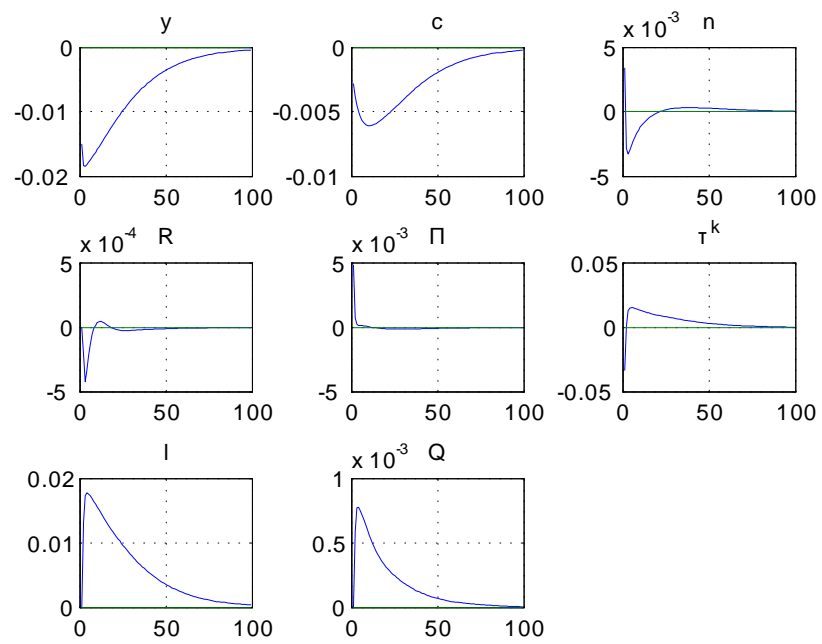
Figure 1d: IRFs to a negative TFP shock

when the fiscal instrument is the labour tax rate
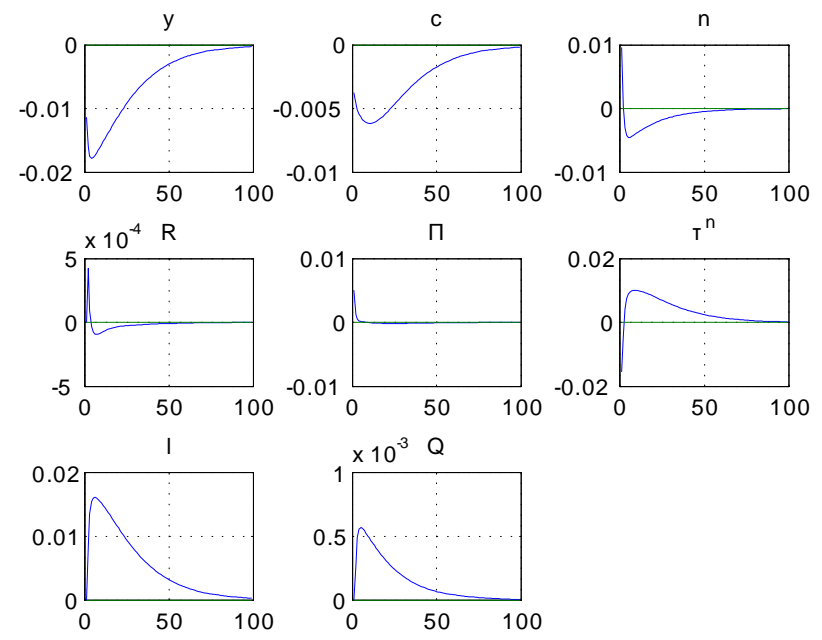

As shown in Figures 1a-d, an adverse TFP shock leads to a contraction in output, $y$, as expected. As a result, government liabilities as a ratio of output, $l$, and sovereign premia, $Q$, rise. Reacting optimally to this cyclical situation, public spending should rise, and tax rates should fall, at impact. In other words, when the economy is hit by an adverse shock, the immediate reaction of fiscal authorities should be to counter the recession by following an expansionary fiscal policy and only, in turn, address debt imbalances by reducing public spending and/or increasing tax rates over time.

\subsection{Robustness}

We now check the robustness of the above results. To save on space, here we just report our main findings (details are available upon request). We have experimented with various changes and the main results do not change. For instance, we have allowed fiscal policy instruments to also react to inflation and the terms of trade. Thus, we have added more indicators to the feedback policy rules in subsection 2.9 above. We report that, other things equal, welfare improves when the fiscal instruments also react to inflation (in the sense that government spending decreases, and taxes increase, when inflation rises above its steady-state value), but the welfare ranking does not change. On the other hand, feedback reaction to the terms of trade should be zero. We also report that assuming a more volatile economy (namely, a higher standard deviation of the TFP shock) does not change our main results. 


\subsection{A fiction: flexible exchange rates}

We finally find it interesting to present the counter-factual case in which Italy would have followed flexible exchange rates over this period. This means that now the exchange rate becomes an endogenous variable, while the nominal interest rate becomes an independently set policy instrument. In particular, following usual practice in related studies (see e.g. Dellas and Tavlas, 2005), we assume that the domestic monetary authorities are free to pursue an active policy following a standard Taylor rule. Thus, we add the following rule for the nominal interest rate, $R_{t}$, to the fiscal rules in subsection 2.9 above:

$$
\log \left(\frac{R_{t}}{R}\right)=\phi_{\pi} \log \left(\frac{\Pi_{t}}{\Pi}\right)+\phi_{y} \log \left(\frac{y_{t}^{H}}{y^{H}}\right)
$$

where $\phi_{\pi}, \phi_{y} \geqq 0$ are new feedback monetary policy coefficients that are computed optimally like the fiscal ones and as explained in subsection 4.2 above.

Results for this policy regime are reported in Table 5. Notice that, in all cases, $\phi_{\pi}>1$, meaning that the Taylor principle should be statisfied, in the sense that monetary policy should react aggressively to inflation (more than one to one). Nevertheless, the main results are not affected, in the sense that there are again no substantial welfare differences among policy instruments used for stabilization. What is more interesting is that monetary independence, in the form of national nominal interest rate policy, may improve welfare relative to the case without monetary independence (compare welfare in Tables 4 and 5), but the welfare gains are negligible. This is in contrast to the popular belief that it would be valuable to be able to use monetary policy, and in particular a nominal exchange rate depreciation, to counter a recession. Note that this appears to be the case even if the model does not incorporate the standard costs from independent monetary policy, in the form of Barro-Gordon (1983) credibility problems, typically arising in inflation-prone countries without commitment mechanisms, as Italy was considered to be before joining the single currency. The inclusion of such costs is expected to make the argument for flexible exchange rates even weaker. ${ }^{10}$ This issue is further discussed below when we present analogous results under debt consolidation.

\footnotetext{
${ }^{10}$ See e.g. Clerk et al. (2009) and Himmels and Kirsanova (2009) for credibity problems in New Keynesian models.
} 
Table 5: Stabilization policy with monetary independence

\begin{tabular}{|c|c|c|c|c|}
\hline $\begin{array}{l}\text { Instruments } \\
\text { used }\end{array}$ & $\begin{array}{l}\text { Optimal reaction } \\
\text { to CPI and output }\end{array}$ & $\begin{array}{l}\text { Optimal reaction } \\
\text { to debt and output }\end{array}$ & $\begin{array}{l}\text { Volatility and } \\
\text { max/min value } \\
\text { of fiscal } \\
\text { instruments }\end{array}$ & $E_{0} V_{0}$ \\
\hline$R_{t} \quad s_{t}^{g}$ & $\begin{array}{c}\phi_{\pi}=3 \\
\phi_{y}=0.03\end{array}$ & $\begin{array}{l}\gamma_{l}^{g}=0.17 \\
\gamma_{y}^{g}=0.11 \\
\end{array}$ & $\begin{array}{c}s t d=0.054 \\
s_{t}^{g}=0.217\end{array}$ & 16.3163 \\
\hline$R_{t} \quad \tau_{t}^{c}$ & $\begin{array}{c}\phi_{\pi}=1.59 \\
\phi_{y}=0\end{array}$ & $\begin{array}{c}\gamma_{l}^{c}=0.17 \\
\gamma_{y}^{c}=0.0076\end{array}$ & $\begin{array}{l}s t d=0.11 \\
\tau_{t}^{c}=0.173\end{array}$ & 16.3191 \\
\hline$R_{t} \quad \tau_{t}^{k}$ & $\begin{array}{c}\phi_{\pi}=1.26 \\
\phi_{y}=0\end{array}$ & $\begin{array}{c}\gamma_{l}^{k}=0.16 \\
\gamma_{y}^{k}=0.0007\end{array}$ & $\begin{array}{c}s t d=0.4 \\
\tau_{t}^{k}=0.325\end{array}$ & 16.318 \\
\hline$R_{t} \quad \tau_{t}^{n}$ & $\begin{array}{c}\phi_{\pi}=3 \\
\phi_{y}=0.04\end{array}$ & $\begin{array}{l}\gamma_{l}^{n}=0.34 \\
\gamma_{y}^{n}=0.25\end{array}$ & $\begin{array}{l}s t d=0.06 \\
\tau_{t}^{n}=0.425\end{array}$ & 16.3192 \\
\hline
\end{tabular}

\section{Stabilization and debt consolidation policy}

We now study the implications of different policies when policymakers do not only stabilize the economy from shocks as in the previous section, but they also reduce the GDP share of public debt over time. In particular, we assume that the government reduces the share of debt from $110 \%$ (which is its average value in the data over the sample period) to $90 \%$. Debt consolidation means three things, at least: First, in the new reformed long run, there are no sovereign risk premia (recall that, in our model, the latter arise whenever public debt happens to be above the $90 \%$ threshold). Second, a reduction in the debt burden allows, other things equal, a cut in the tax rates, and/or a rise in public spending, in the long run, although this comes at the cost of higher taxes and/or lower public spending during the early phase of the transition path. Third, technically speaking, now there are two sources of transition dynamics: temporary shocks and the difference between the initial and the new reformed steady state (see also Cantore et al., 2012).

These issues are discussed in some detail in the following subsection.

\subsection{How we model debt consolidation}

It is well recognized that the implications of fiscal reforms, like debt consolidation, depend heavily on the public financing policy instrument used, namely, which policy instrument adjusts endogenously to accommodate the exogenous changes in fiscal policy (see e.g. Leeper et al., 
2010, and Leeper, 2010). Here, we will assume that, along the transition path, debt reforms are accommodated by adjustments in the tax-spending policy instruments, namely, the output share of public spending, and the tax rates on capital income, labour income and consumption. To understand the logic of our results, and following usual practice in related studies, we will experiment with one fiscal instrument at a time. This means that, along the transition path, we allow one of the fiscal policy instruments to react to public debt imbalances, so as to stabilize debt around its new target value of 0.9 and, at the same time, the same fiscal policy instrument adjusts residually in the long run to close the government budget. Thus, the policy rules for these instruments are as in section 2.9 above except that now the targetted, or long-run, values are those of the reformed long-run equilibrium. All other fiscal policy instruments, except the one used for stabilization, remain unchanged and equal to the pre-reform steady-state values. The feedback policy coefficients of the fiscal policy instrument used for stabilization along the transition path, as well as the feedback policy coefficients of the nominal interest rate, are chosen optimally as explained in subsection 4.2 and as we did in the previous section.

In particular, we work as follows. We first solve and compare the long-run equilibria with and without debt consolidation. In turn, setting, as initial conditions for the state variables, their steady state solution of the economy without debt consolidation (see the status quo long-run solution in subsection 3.2), we compute the equilibrium transition path of each reformed economy under optimized policy rules and in turn compute the associated conditional discounted lifetime utility of the household. This is for each method of public financing used.

\subsection{Optimized policy rules}

We report that the determinacy areas remain as above. Nevertheless, we now need to restrict the feedback fiscal coefficients on public debt, $\gamma_{l}^{q}$, where $q \equiv\left(s^{g}, \tau^{c}, \tau^{k}, \tau^{n}\right)$, in order to get economically meaningful solutions for the fiscal instruments, i.e. in order to get $0 \leq \tau_{t}^{c}, \tau_{t}^{k}, \tau_{t}^{n}<$ 1. In particular, in this section, we work within a narrower range for $\gamma_{l}^{q}$, which is $\gamma_{l}^{q} \in[0.1,0.2]$. This makes sense. When debt consolidation is among the policy aims, the fiscal authorities may find it optimal to increase tax rates, and/or reduce public spending, beyond meaningful or historical ranges. Our simulations imply that this applies in particular to the capital tax rate, $\tau_{t}^{k}$, which, if it is left free, it can easily rise above $100 \%$ in the short run due to the high value of $\gamma_{l}^{k}$ chosen (this is consistent with the Ramsey-Chamley result that, since capital is inelastic in the very short, the fiscal authorities may find it optimal to confiscate it). To avoid such problems, we restrict ourselves within $\gamma_{l}^{q} \in[0.1,0.2]$. Note that such practice is usual both in the policy literature (see e.g. Cantore et al., 2012), as well as in the theoretical literature 
on optimal taxation (see e.g. Chamley, 1986). We finally report that the equilibrium nominal interest rate is above the zero bound in all solutions reported below.

Within the above ranges, we now turn to optimized policy rules. Results are reported in Table 6. This Table includes the same information as before except that we now add a new column (see the last one), which reports the percentage difference in conditional welfare, $E_{0} V_{0}$, when we compare a particular policy instrument vis-a-vis the best (or the least distorting) one. ${ }^{11}$ For instance, in Table 6 , the best instrument is the consumption tax rate, $\tau_{t}^{c}$, so the negative numbers in the last column report the welfare loss in case we use one of the other suboptimal instruments, $s_{t}^{g}, \tau_{t}^{k}$ and $\tau_{t}^{n}$, vis-a-vis $\tau_{t}^{c}$.

Table 6: Stabilization and debt consolidation policy without monetary independence

\begin{tabular}{ccccc}
\hline \hline $\begin{array}{c}\text { Fiscal } \\
\text { instrument }\end{array}$ & $\begin{array}{c}\text { Optimal reaction } \\
\text { to debt and output }\end{array}$ & $\begin{array}{c}\text { Volatility and } \\
\text { max/min value of } \\
\text { instruments }\end{array}$ & $E_{0} V_{0}$ & $\begin{array}{c}\text { Welfare loss } \\
\text { vis-a-vis } \tau_{t}^{c}\end{array}$ \\
\hline \hline \multirow{2}{*}{$s_{t}^{g}$} & $\gamma_{l}^{g}=0.15$ & $s t d=0.042$ & 23.4210 & $-2.24 \%$ \\
& $\gamma_{y}^{g}=0.0005$ & $s_{t}^{g}=0.13$ & \\
\hline \hline \multirow{2}{*}{$\tau_{t}^{c}$} & $\gamma_{l}^{c}=0.2$ & $s t d=0.085$ & \multirow{2}{*}{23.9590} & - \\
\hline \hline & $\gamma_{y}^{c}=0.0007$ & $\tau_{t}^{c}=0.41$ & & $-358 \%$ \\
\hline \hline & $\gamma_{l}^{k}=0.13$ & $s t d=0.14$ & -61.8754 & $-1.53 \%$ \\
$\tau_{t}^{n}$ & $\gamma_{y}^{k}=0$ & $\tau_{t}^{k}=0.81$ & & \\
\hline \hline
\end{tabular}

The results show that the welfare ranking is consumption taxes first, and in turn labor taxes and public spending, while capital taxes are by far the worst fiscal policy choice to make. The desirability of consumption taxes over other taxes, in a semi-small open economy with sovereign premia, is consistent with the results of Bi (2010), although Bi uses a real, simpler model. Keep in mind that these results are in terms of lifetime utility because shorter time horizons may imply different things. We thus prefer to postpone the discussion of these results until later when we also present different time horizons.

Nevertheless, it is important to point out that, other things equal, debt consolidation improves welfare, except from the case in which we use a particularly distorting policy instrument like the capital tax rate. This follows by comparing the computed lifetime utility in Tables 4

\footnotetext{
${ }^{11}$ To compare regimes, we could alternatively use a flat consumption subsidy that makes the agent indifferent between two regimes (see e.g. Lucas, 1990). The message will be the same.
} 
and 6. The values of $E_{0} V_{0}$ are much higher in Table 6 , except when we use $\tau_{t}^{k}$. It is worth pointing out that the rise in welfare is partly driven by the fact that debt consolidation and elimination of sovereign premia in the reformed long-run equilibrium allow a higher value of the time preference rate than in the pre-reformed long-run solution in section 3 (in particular, the calibrated value of $\beta$ was 0.9603 in the status quo solution in section 3 , while it is 0.9709 now without premia).

\subsection{Impulse response functions under optimized policy rules}

We now present the associated impulse responce functions (IRFs) of some key endogenous variables when there is a negative TFP shock (as we had in section 5 above) and, at the same time, we reduce public debt over time as defined above. Results under the four fiscal policy instruments, $s_{t}^{g}, \tau_{t}^{c}, \tau_{t}^{k}$ and $\tau_{t}^{n}$, are shown in Figures 2a-d respectively (as above, variables in IRFs are expressed as log-deviations from their long-run values).

Figure 2a: IRFs when the economy travels from the status-quo to the reformed steady-state and there is a negative TFP shock while the fiscal instrument is government spending
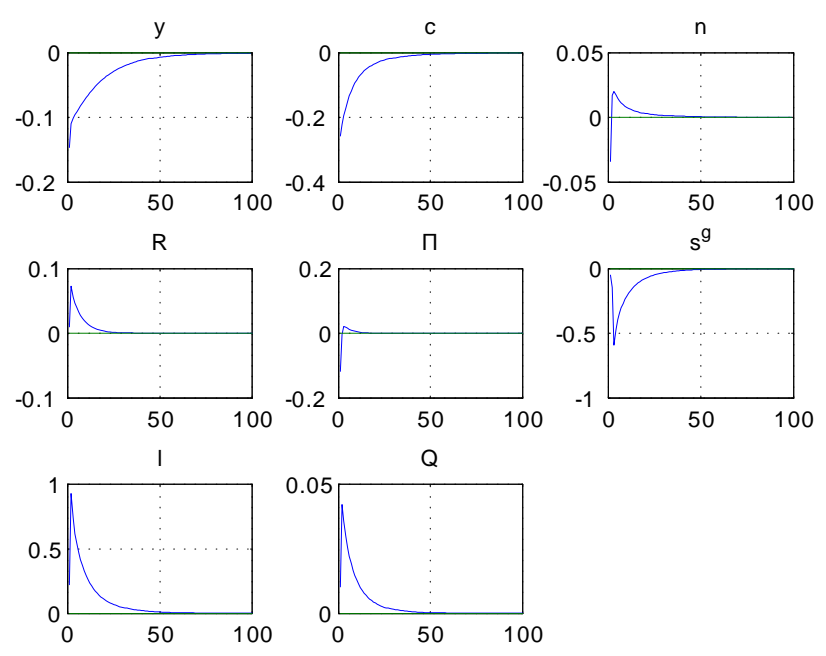
Figure 2b: IRFs when the economy travels from the status-quo to the reformed steady-state and there is a negative TFP shock while the fiscal instrument is the consumption tax rate
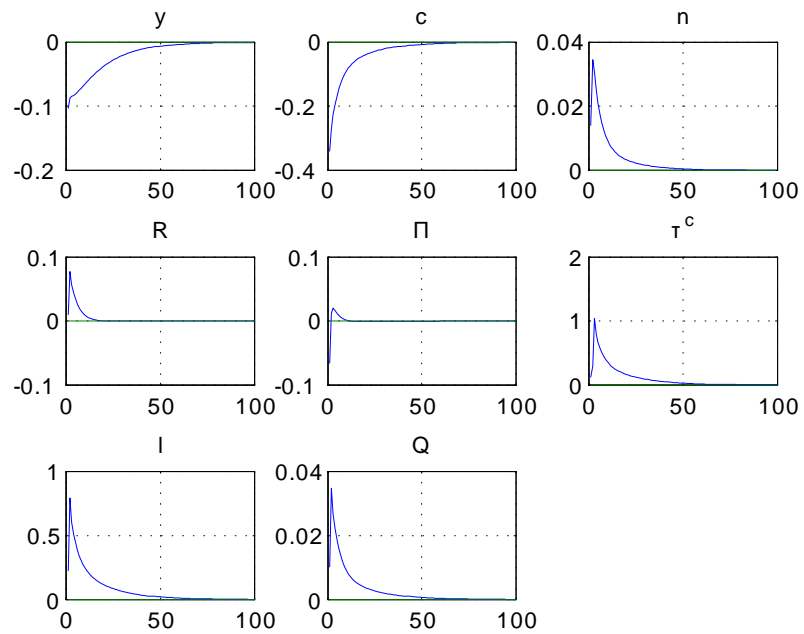

Figure 2c: IRFs when the economy travels from the status-quo to the reformed steady-state and there is a negative TFP shock while the fiscal instrument is the capital tax rate
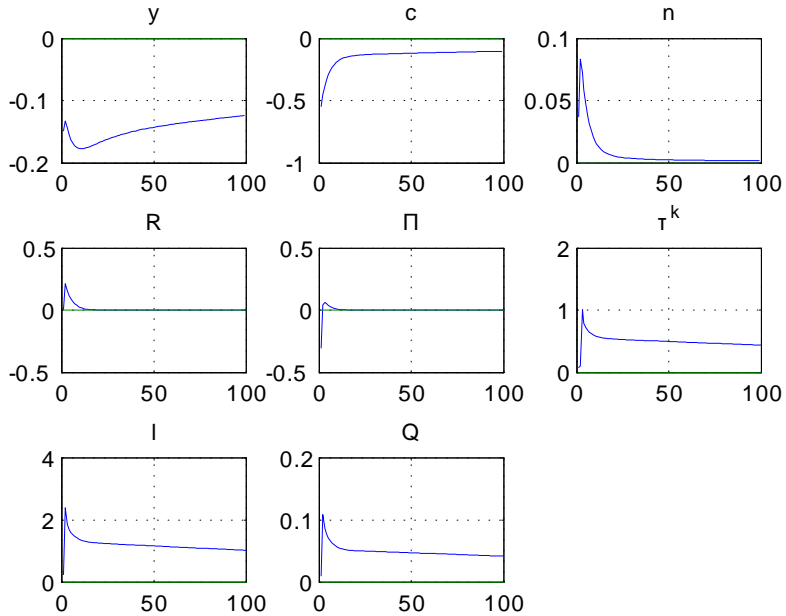
Figure 2d: IRFs when the economy travels from the status-quo to the reformed steady-state and there is a negative TFP shock while the fiscal instrument is the labour tax rate
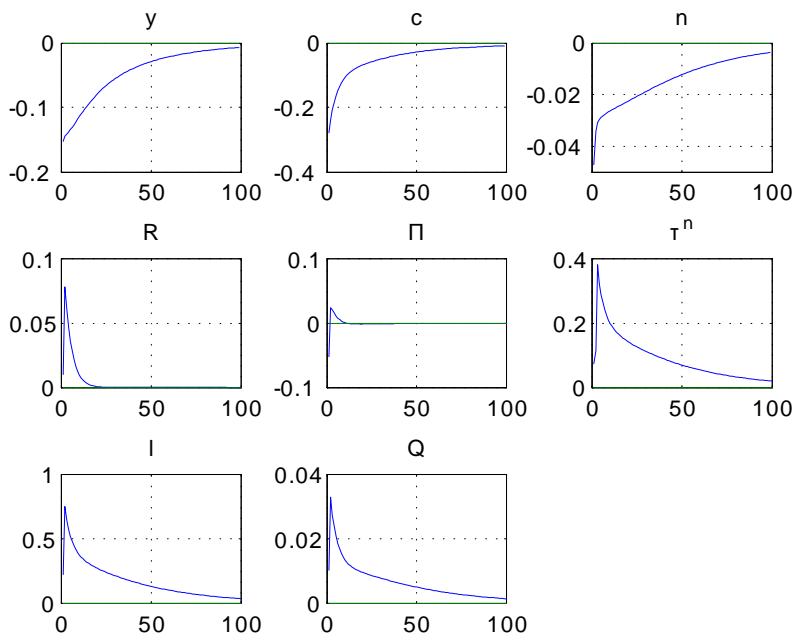

Figures 2a-d imply that public spending should fall, and tax rates should rise. In other words, the concern for debt consolidation more than offsets the concern for shock stabilization, even when the economy is hit an adverse shock. This is the opposite from Figures 1a-d above. In Figures 1a-d, all fiscal instruments gave priority to the business cycle at impact, and only then were used to address debt imbalances. By constrast, now, changes in all fiscal instruments are driven by debt imbalances all the time.

To make our results clearer, Figure 3 also presents the implied total public debt as share of output (as a rate rather than as deviation of this rate from its long-run value which was the case in the IRFs above). As can be seen, debt starts at 110\%, which is its status quo value, and ends up at $90 \%$ in the new reformed long run. In the very short run, the economy is hit by an adverse shock that reduces ouput and increases the debt share but then, thanks to active fiscal consolidation, debt starts falling towards its $90 \%$ threshold. This figure also confirms that the use of the capital tax rate is problematic.

Finally, inspection of Figures 2 and 3 implies that the duration of the debt consolidation phase, and so the speed of debt reduction, depend on which fiscal instrument we use. If we use the consumption tax rate, $\tau_{t}^{c}$, or the public spending ratio, $s_{t}^{g}$, it is optimal to reduce the debt ratio from $110 \%$ to $90 \%$ within 60 periods, while if we use the labor tax rate, $\tau_{t}^{n}$, in more than 100 periods. Thus, the more distorting is the instrument used, the longer the period of adjustment should be. 
Figure 3: The path of public debt as share of output

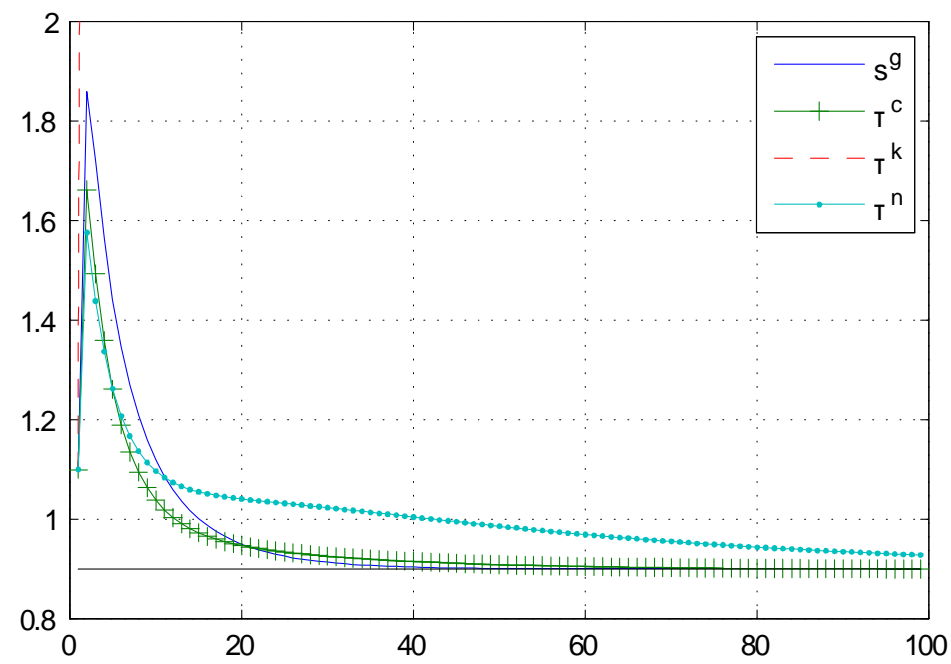

\subsection{Shorter time horizons}

We now study what happens if we do not care about lifetime utility but about shorter time horizons. This is important because, for several reasons, economic agents' behavior can be short termist. Setting the feedback policy coefficients as in Table 6 above, the expected discounted utility at various time horizons is reported in Table $7 .^{12}$

The results in Table 7 show that if we care about 10 periods only, then the capital tax is the least distorting policy instrument. This follows the Ramsey-Chamley logic mentioned above. Namely, capital taxes, if they are imposed in the very short run, they work as a tax on wealth, or a capital levy, so that they are less distorting than other taxes, especially since high capital taxes in the very short can allow low capital taxes in the future, the expectation of which can stimulate investment. However, as we start to become more far-sighted, the capital tax proves to be a very bad idea. Note that the restrictions imposed on the value of $\gamma_{l}^{k}$, and effectively on the value of $\tau_{t}^{k}$, are important because, if these values were left unrestricted, then the government could impose a huge capital tax in the very short run and enjoy low taxes soon. By imposing these restrictions on $\gamma_{l}^{k}$ and $\tau_{t}^{k}$, and thus by not allowing this to happen, the government has to use capital taxes for a number of periods, given the size of debt consolidation required, and this proves to be very damaging.

\footnotetext{
${ }^{12}$ The quantitative difference between welfare over 500 periods and lifetime welfare is due to the fact that they are computed differently. The qualitative ranking is the same, however.
} 
Table 7: Welfare at various time horizons

\begin{tabular}{cccccc}
\hline \hline Fiscal Instrument & 4 periods & 10 periods & 50 periods & 500 periods & $E_{0} V_{0}$ \\
\hline \hline$s_{t}^{g}$ & 2.5376 & 5.6465 & 17.1325 & 22.8194 & 23.4210 \\
\hline \hline$\tau_{t}^{c}$ & 2.7184 & 5.9918 & 17.8445 & 23.6162 & 23.9590 \\
\hline \hline$\tau_{t}^{k}$ & 3.9799 & 7.1171 & -18.82 & -66.3103 & -61.8754 \\
\hline \hline$\tau_{t}^{n}$ & 2.7266 & 6.2913 & 17.8940 & 23.3251 & 23.5912 \\
\hline \hline
\end{tabular}

Figure 4 also shows the time path of those endogenous variables that directly affect welfare. The capital tax rate proves to be particulary bad for output over time (roughly speaking, after the 10th period).

Figure 4: The path of variables shaping welfare
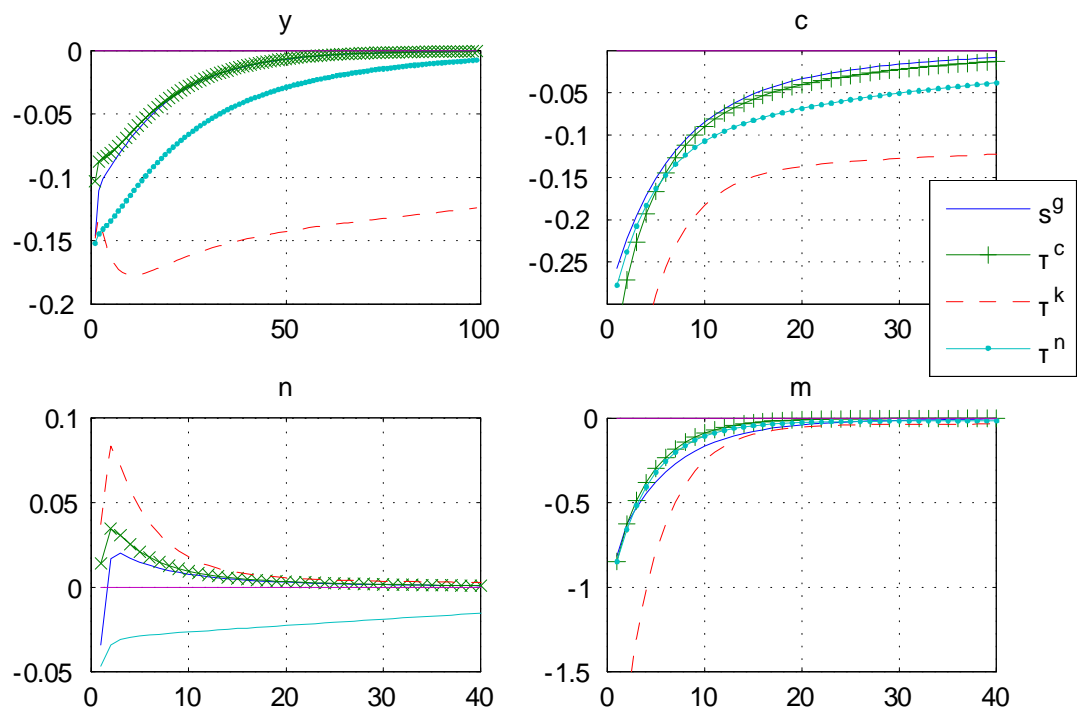

\subsection{Robustness}

We report that our results above are robust to several changes like those discussed in the previous section. For instance, they are robust to adding new indicators in the policy rules, assuming a more volatile economy, small changes in parameter values, etc.

\subsection{A fiction: flexible exchange rates}

We finally study what would happen in the fictional case in where Italy enjoyed monetary policy independence. Results are reported in Table 8. The last column reports the welfare gain when Italy follows this fictional policy vis-a-vis the actual case without monetary policy independence 
(see Table 6 above). The results show that now the welfare gains are not negligible. That is, our results provide some support to the argument that having monetary policy independence can be valuable in case of debt consolidation. Nevertheless, we need to be cautious here and not draw any conclusions about the desirability of alternative exchange rate regimes because our model does not incorporate credibility issues that might arise in case of flexible exchange rates and which would weaken the benefits from independent monetary policy.

Table 8: Stabilization and debt consolidation policy with monetary independence

\begin{tabular}{|c|c|c|c|c|c|}
\hline $\begin{array}{l}\text { Instruments } \\
\text { used }\end{array}$ & $\begin{array}{c}\text { Optimal reaction } \\
\text { to inflation } \\
\text { and output }\end{array}$ & $\begin{array}{c}\text { Optimal reaction } \\
\text { to debt } \\
\text { and output }\end{array}$ & $\begin{array}{l}\text { Volatility and } \\
\text { max/min value } \\
\text { of fiscal } \\
\text { instruments }\end{array}$ & $E_{0} V_{0}$ & $\begin{array}{l}\text { Welfare gain } \\
\text { vis-a-vis fixed } \\
\text { exchange rates }\end{array}$ \\
\hline$R_{t} \quad s_{t}^{g}$ & $\begin{array}{c}\phi_{\pi}=3 \\
\phi_{y}=0.01 \\
\end{array}$ & $\begin{array}{c}\gamma_{l}^{g}=0.2 \\
\gamma_{y}^{g}=0.0042\end{array}$ & $\begin{array}{c}s t d=0.04 \\
s_{t}^{g}=0.11\end{array}$ & 24.4680 & $4.47 \%$ \\
\hline$R_{t} \quad \tau_{t}^{c}$ & $\begin{array}{c}\phi_{\pi}=1.81 \\
\phi_{y}=0 \\
\end{array}$ & $\begin{array}{c}\gamma_{l}^{c}=0.2 \\
\gamma_{y}^{c}=0.0047\end{array}$ & $\begin{array}{c}s t d=0.09 \\
\tau_{t}^{c}=0.39\end{array}$ & 25.1974 & $5.17 \%$ \\
\hline$R_{t} \quad \tau_{t}^{k}$ & $\begin{array}{c}\phi_{\pi}=1.36 \\
\phi_{y}=0\end{array}$ & $\begin{array}{c}\gamma_{l}^{k}=0.2 \\
\gamma_{y}^{k}=0.0001\end{array}$ & $\begin{array}{c}s t d=0.06 \\
\tau_{t}^{k}=0.49\end{array}$ & 0.2221 & $100 \%$ \\
\hline$R_{t} \quad \tau_{t}^{n}$ & $\begin{array}{c}\phi_{\pi}=1.3 \\
\phi_{y}=0\end{array}$ & $\begin{array}{c}\gamma_{l}^{n}=0.19 \\
\gamma_{y}^{n}=0\end{array}$ & $\begin{array}{c}s t d=0.05 \\
\tau_{t}^{n}=0.55\end{array}$ & 24.6861 & $4.64 \%$ \\
\hline
\end{tabular}

Despite these welfare reservations, it is informative to present, in Figure 5, the impulse response functions of the gross change in the exchange rate as deviation from its long run value, $\widehat{\epsilon}_{t}$, corresponding to the four mixes of monetary and fiscal policy as reported in the four rows of Table 8 . When the economy is hit by an adverse TFP shock and the fiscal authorities gradually reduce public debt to its $90 \%$ threshold, the optimized policy rules imply an exchange rate depreciation in the very short run (see Figure 5). This is translated into an improvement in the terms of trade (see Figure 6). 
Figure 5: IRFs of the exchange rate

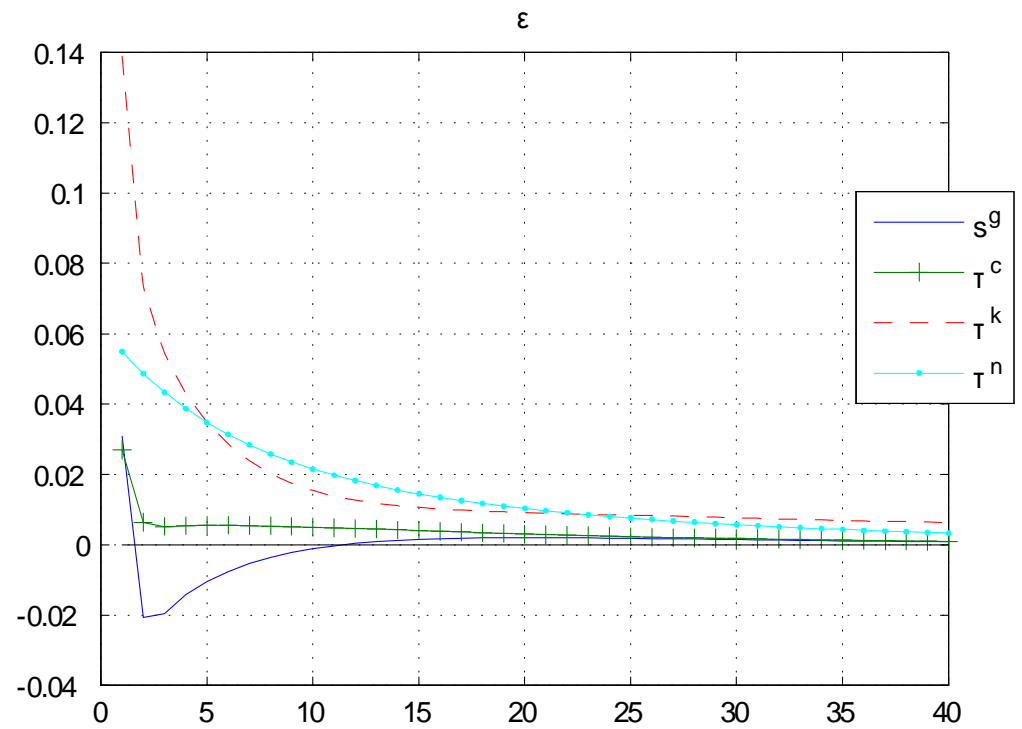

Figure 6: IRFs of the terms of trade

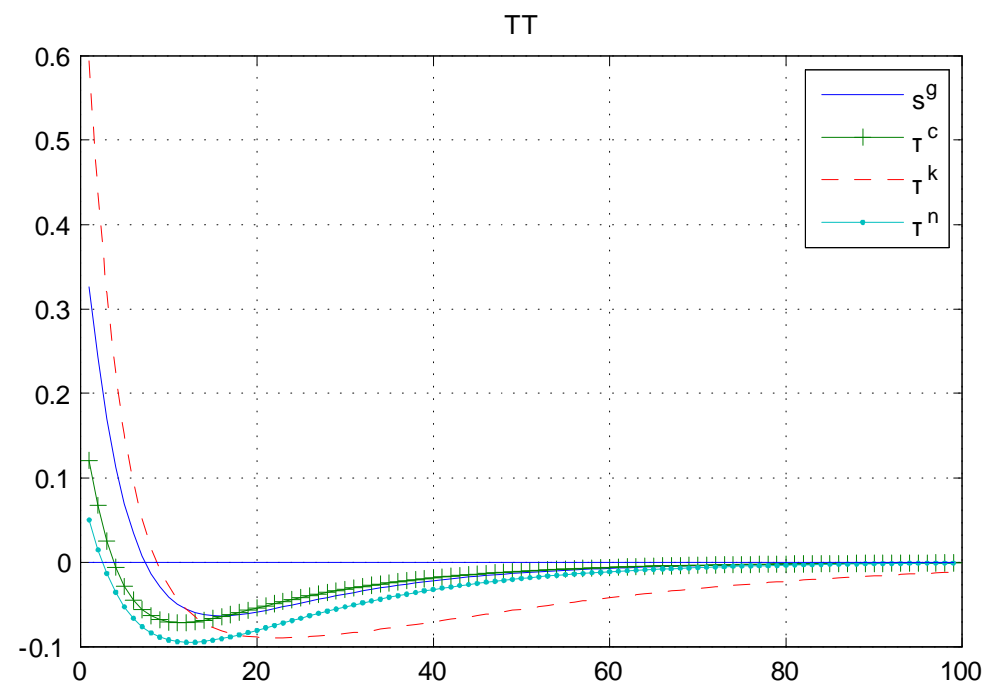

\section{Concluding remarks}

This paper has studied fiscal policy in a New Keynesian model of a semi-small open economy facing endogenous sovereign risk premia and not being able to use monetary policy. The focus has been on optimized simple and implementable policy rules for various categories of taxes and public spending. 
Since the results are written in the Introduction, we close with some possible extensions. It would be interesting to add heterogeneity both in terms of economic agents within a country and in terms of countries. In particular, we could distinguish between private and public employees and so see the distributional implications of the policies studied here. The related literature has used representative household models so issues of distribution have not been studied. It is also interesting to use a two-country model, where countries can differ in, say, fiscal imbalances and/or preferences and so study the cross-border effects of national stabilization and debt consolidation policies. We leave these extensions for future work. 


\section{References}

[1] Andrès J. and Doménech R., 2006. Automatic stabilizers, fiscal rules and macroeconomic stability. European Economic Review, 50, 1487-1506.

[2] Ardagna S., Caselli F. and Lane T., 2004. Fiscal discipline and the cost of public debt service: Some estimates for OECD Countries. Working Paper no. 411, European Central Bank.

[3] Benigno G., Benigno P. and Ghironi F., 2007. Interest rate rules for fixed exchange regimes. Journal of Economic Dynamics and Control, 31, 2196-2211.

[4] Benigno G. and Benigno P., 2008. Exchange rate determination under interest rate rules. Journal of International Money and Finance, 27, 971-993.

[5] Benigno G., and Thoenissen C., 2003. Equilibrium exchange rates and supply-side performance. Economic Journal, 113, 103-124.

[6] Bi H., 2010. Optimal debt targeting rules for small open economies. Mimeo.

[7] Bi H. and Kumhof, 2011. Jointly optimal monetary and fiscal policy rules under liquidity constraints. Journal of Macroeconomics, 33, 373-389.

[8] Bi H. and Leeper E., 2010. Sovereign debt risk premia and fiscal policy in Sweden. Mimeo.

[9] Bi H., Leeper E. and Leigh C., 2012. Uncertain fiscal consolidations. Mimeo.

[10] Cantore C., Levine P., Melina G. and Pearlman J., 2012. Optimal fiscal and monetary rules in normal and abnormal times. Mimeo, University of Surrey.

[11] Clerk L., Dellas H., and Loisel O., 2009. To be or not to be in a monetary union: A synthesis. Mimeo, University of Bern.

[12] Cogan J., Taylor J., Wieland V. and Wolters M., 2013. Fiscal consolidation strategy. Journal of Economic Dynamics and Control, 37, 404-421.

[13] Collard F. and Dellas H., 2006. Price rigidity and the selection of the exchange rate regime. Open Economies Review, 17, 5-26.

[14] Christiano L., Trabandt M. and Walentin K., 2010: Introducing financial frictions and unemployment into a small open economy model. Mimeo. 
[15] Dellas H. and Tavlas G., 2005. Wage rigidity and monetary union. Economic Journal, 115, 907-927.

[16] Diz Dias J., 2010. External debt statistics of the euro area. Mimeo, European Central Bank.

[17] Erceg C. and Linde J., 2013. Fiscal consolidation in a currency union. Journal of Economic Dynamics and Control, 37, 422-445.

[18] Fahr S. and Smets F., 2010. Downward wage rigidities and optimal monetary policy in a monetary union. Scandinavian Journal of Economics 112, 812-840.

[19] Forni L., Gerali A. and Pisani M., 2010. The macroeconomics of fiscal consolidation in euro area countries. Journal of Economic Dynamics and Control, 34, 1791-1812.

[20] Gali J. and Monacelli T., 2005: Monetary policy and exchange rate volatility in a small open economy. Review of Economic Studies, 72, 707-734.

[21] Gali J. and Monacelli T., 2008: Optimal monetary and exchange rate policy in a currency union. Journal of International Economics, 76, 116-132.

[22] Gali J., 2008. Monetary Policy, Inflation and the Business Cycle: An Introduction to the New Keynesian Framework. Princeton University Press.

[23] Gordon D. and Leeper E., 2003. Are countercyclical fiscal policies counterproductive?. Mimeo.

[24] Himmels C. and Kirsanova T., 2009. The interest rate-exchange rate nexus: exchange rate regimes and policy equilibria. Mimeo.

[25] Kazanas T., Philippopoulos A. and Tzavalis E., 2012. Monetary policy rules and business cycle conditions. Manchester School, forthcoming.

[26] Kirsanova T., Satchi M., Vines D. and Wren-Lewis S., 2007. Optimal fiscal policy rules in a monetary union. Journal of Money Credit and Banking, 39, 1759-1784.

[27] Kirsanova T., Leith C., and Wren-Lewis S., 2009. Monetary and fiscal policy interaction: the current consensus assignment in the light of recent developments. Economic Journal, 119, F482-F495.

[28] Kirsanova T. and Wren-Lewis S., 2012. Optimal fiscal feedback on debt in an economy with nominal rigidities. Economic Journal, 122, 238-264. 
[29] Leeper E. 1991. Equilibria under active and passive monetary and fiscal policies. Journal of Monetary Economics, 27, 129-147.

[30] Leeper E., Plante M. and Traum N., 2009. Dynamics of fiscal financing in the United States. Journal of Econometrics, 156, 304-321.

[31] Leith C. and Wren-Lewis S., 2008. Interactions between monetary and fiscal policy under flexible exchange rates. Journal of Economic Dynamics and Control, 32, 2854-2882.

[32] Monacelli T., 2004. Into the Mussa puzzle: Monetary policy regimes and the real exchange rate in a small open economy. Journal of International Economics, 62, 191-217.

[33] Malley J., Philippopoulos A. and Woitek U., 2009. To react or not? Technology shocks, fiscal policy and welfare in the EU-3. European Economic Review, 689-714.

[34] Obstfeld M. and Taylor A., 2003. Sovereign risk, credibility and the gold standard. Economic Journal, 113, 241-275.

[35] Papageorgiou D., 2012. Fiscal policy reforms in general equilibrium: The case of Greece. Journal of Macroeconomics, forthcoming.

[36] Pappa E. and Neiss K., 2005. Persistence without too much price stickiness: The role of factor utilization. Review of Economics Dynamics, 8, 231-255.

[37] Pappa E. and Vassilatos V., 2007. The unbearable tightness of being in a monetary union: Fiscal restrictions and regional stability. European Economic Review, 51, 1492-1513.

[38] Philippopoulos A., Varthalitis P. and Vassilatos V., 2012. On the optimal mix of monetary and fiscal policy actions. Bank of Greece, Working Paper, no. 150.

[39] Reinhart C. and Rogoff K., 2010. Growth in a time of debt, American Economic Review, $100,573-578$.

[40] Schmitt-Grohé S. and Uribe M., 2003. Closing small open economies. Journal of International Economics, 61, 163-185.

[41] Schmitt-Grohé S. and Uribe M., 2004. Solving dynamic general equilibrium models using a second-order approximation to the policy function. Journal of Economic Dynamics and Control 28, 755-775.

[42] Schmitt-Grohé S. and Uribe M., 2005. Optimal fiscal and monetary policy in a mediumscale macroeconomic model. In Gertler M. and Rogoff K., eds., NBER Macroeconomics Annual, MIT Press, Cambridge MA, 385-425. 
[43] Schmitt-Grohé S. and Uribe M., 2007. Optimal simple and implementable monetary and fiscal rules. Journal of Monetary Economics, 54, 1702-1725.

[44] Schmitt-Grohé S. and Uribe M., 2011. Pegs and pain. Mimeo.

[45] Wickens M., 2008. Macroeconomic Theory: A Dynamic General Equilibrium Approach. Princeton University Press.

[46] Wren-Lewis S., 2010. Macroeconomic policy in light of the credit crunch: the return of counter-cyclical fiscal policy? Oxford Review of Economic Policy, 26, 71-86.

[47] Yun T., 1996. Nominal price rigidity, money supply endogeneity and business cycles. Journal of Monetary Economics, 37, 345-370. 


\section{Appendices}

\subsection{Appendix 1: Modelling fixed exchange rates}

The related literature on exchange rate regimes (see e.g. Monacelli, 2004, Gali and Monacelli, 2005, Benigno et al., 2007, Benigno and Benigno, 2008) starts by assuming an independent monetary authority which sets the nominal interest rate, $R_{t}$, according to a Taylor-type rule according to which the interest rate also feeds back on the gross depreciation rate, $\epsilon_{t}$. Then, they model the fixed exchange rate regime as a polar case of that rule by setting a very large value for the feedback coefficient on $\epsilon_{t}$; practically, a value that makes $\epsilon_{t}$ close to one. This is like having fixed exchange rates in equilibrium or ex post (see also the discussion in Himmels and Kirsanova , 2009). In our paper, to have fixed exchange rates both ex post and ex ante, we follow a more direct modelling approach. Under a fixed exchange rate regime, we set $\epsilon_{t}$ exogenously at unity. Then, as mentioned above, we have to make one of the other policy instruments, $R_{t}, \tau_{t}^{c}, \tau_{t}^{k}, \tau_{t}^{n}, \tau_{t}^{b}, \tau_{t}^{f}, s_{t}^{g}, s_{t}^{l}, b_{t}$, endogenous to close the model. We have exterimented with two choices: In the first, the endogenous variable is $R_{t}$. In the second, one of $s_{t}^{g}, s_{t}^{l}, b_{t}$ is the endogenous variable. The former case is closer to being a member of a currency union, in the sense that the country keeps the exchange rate fixed and, at the same time, sacrifices monetary policy independence. The latter case is the textbook case of a country that fixes its currency but, thanks to imperfect capital mobility (here, generated by the endogenous world interest rate), can still use its monetary policy. Our numerical solutions below imply that in the latter case, namely if we try to use $b_{t}, s_{t}^{l}$ or $s_{t}^{g}$ as the endogenous variable, we always come up with an unstable equilibrium. Thus, in what follows, we report results only for the case in which $R_{t}$ is endogenous, namely we lose monetary policy independence, with the nominal domestic interest rate being determined by the world interest rate (which is exogenous) and the country's risk premium (which is endogenous).

\subsection{Appendix 2: Decentralized equilibrium (given policy)}

The Decentralized Equilibrium (DE) is summarized by the following 22 equations (quantities are in per capita terms):

$$
\begin{gathered}
\frac{\partial u_{t}}{\partial c_{t}} \frac{\partial c_{t}}{\partial c_{t}^{H}} \frac{1}{\left(1+\tau_{t}^{c}\right)} \frac{P_{t}}{P_{t}^{H}}=\beta E_{t} \frac{\partial u_{t+1}}{\partial c_{t+1}} \frac{\partial c_{t+1}}{\partial c_{t+1}^{H}} \frac{1}{\left(1+\tau_{t+1}^{c}\right)} \frac{P_{t+1}}{P_{t+1}^{H}} R_{t} \frac{P_{t}}{P_{t+1}} \\
\frac{\partial u_{t}}{\partial c_{t}} \frac{\partial c_{t}}{\partial c_{t}^{H}} \frac{1}{\left(1+\tau_{t}^{c}\right)} \frac{P_{t}}{P_{t}^{H}} \frac{S_{t} P_{t}^{*}}{P_{t}}\left(1+\phi^{p}\left(\frac{S_{t} P_{t}^{*}}{P_{t}} f_{t}^{h}-\frac{S P^{*}}{P} f^{h}\right)\right) \\
\beta \frac{\partial u_{t+1}}{\partial c_{t+1}} \frac{\partial c_{t+1}}{\partial c_{t+1}^{H}} \frac{1}{\left(1+\tau_{t+1}^{c}\right)} \frac{P_{t+1}}{P_{t+1}^{H}} Q_{t} \frac{S_{t+1} P_{t+1}^{*}}{P_{t+1}} \frac{P_{t}^{*}}{P_{t+1}^{*}}
\end{gathered}
$$




$$
\begin{aligned}
& \frac{\partial u_{t}}{\partial c_{t}} \frac{\partial c_{t}}{\partial c_{t}^{H}} \frac{1}{\left(1+\tau_{t}^{c}\right)}\left\{1+\xi\left(\frac{k_{t}}{k_{t-1}}-1\right)\right\} \\
& =\beta E_{t} \frac{\partial u_{t+1}}{\partial c_{t+1}} \frac{\partial c_{t+1}}{\partial c_{t+1}^{H}} \frac{1}{\left(1+\tau_{t+1}^{c}\right)}\left\{(1-\delta)-\frac{\xi}{2}\left(\frac{k_{t+1}}{k_{t}}-1\right)^{2}+\xi\left(\frac{k_{t+1}}{k_{t}}-1\right) \frac{k_{t+1}}{k_{t}}+\left(1-\tau_{t+1}^{k}\right) r_{t+1}^{k}\right\} \\
& \chi_{m} \frac{\partial u_{i, t}}{\partial m_{i, t}}=\frac{\partial u_{i, t}}{\partial c_{i, t}} \frac{\partial c_{i, t}}{\partial c_{i, t}^{H}} \frac{1}{\left(1+\tau_{t}^{c}\right)} \frac{P_{t}}{P_{t}^{H}}-\beta E_{t} \frac{\partial u_{i, t+1}}{\partial c_{i, t+1}} \frac{\partial c_{i, t+1}}{\partial c_{i, t+1}^{H}} \frac{1}{\left(1+\tau_{t+1}^{c}\right)} \frac{P_{t+1}}{P_{t+1}^{H}} \frac{P_{t}}{P_{t+1}} \\
& \chi_{n} \frac{\partial u_{t}}{\partial n_{t}}=\frac{\partial u_{t}}{\partial c_{t}} \frac{\partial c_{t}}{\partial c_{t}^{H}} \frac{P_{t}}{P_{t}^{H}} \frac{\left(1-\tau_{t}^{n}\right)}{\left(1+\tau_{t}^{c}\right)} w_{t} \\
& \frac{c_{t}^{H}}{c_{t}^{F}}=\frac{\nu}{1-\nu} \frac{P_{t}^{F}}{P_{t}^{H}} \\
& k_{t}=(1-\delta) k_{t-1}+x_{t}-\frac{\xi}{2}\left(\frac{k_{t}}{k_{t-1}}-1\right)^{2} k_{t-1} \\
& c_{t} \equiv \frac{\left(c_{t}^{H}\right)^{\nu}\left(c_{t}^{F}\right)^{1-\nu}}{\nu^{\nu}(1-\nu)^{1-\nu}} \\
& w_{t}=m c_{t}(1-a) \frac{y_{t}}{n_{t}} \\
& \frac{P_{t}^{H}}{P_{t}} r_{t}^{k}=m c_{t} a \frac{y_{t}}{k_{t-1}} \\
& D_{t}=P_{t}^{H} y_{t}^{H}-r_{t}^{k} P_{t}^{H} k_{t-1}-W_{t} n_{t} \\
& \sum_{k=0}^{\infty}(\theta)^{k} E_{t} \Xi_{t, t+k}\left[\frac{P_{t}^{\#}}{P_{t+k}^{H}}\right]^{-\phi} y_{t+k}^{H}\left\{\frac{P_{t}^{\#}}{P_{t}}-\frac{\phi}{\phi-1} m c_{t+k} \frac{P_{t+k}}{P_{t}}\right\}=0 \\
& y_{t}^{H}=\frac{1}{\left[\frac{\widetilde{P}_{t}^{H}}{P_{t}^{H}}\right]^{-\phi}} A_{t} k_{t-1}^{a} n_{t}^{1-a} \\
& b_{t}+m_{t}+\frac{S_{t} P_{t}^{*}}{P_{t}} f_{t}^{g}=\frac{\phi^{g}}{2}\left(\frac{S_{t} P_{t}^{*}}{P_{t}} f_{t}^{g}-\frac{S P^{*}}{P} f^{g}\right)^{2}+\frac{R_{t-1} b_{t-1}}{\Pi_{t}}+\frac{m_{t-1}}{\Pi_{t}}+ \\
& Q_{t-1} \frac{S_{t} P_{t}^{*}}{P_{t}} \frac{P_{t-1}^{*}}{P_{t}^{*}} f_{t-1}^{g}+\frac{P_{t}^{H}}{P_{t}} g_{t}-\tau_{t}^{c}\left(\frac{P_{t}^{H}}{P_{t}} c_{t}^{H}+\frac{P_{t}^{F}}{P_{t}} c_{t}^{F}\right)-\tau_{t}^{k}\left(r_{t}^{k} \frac{P_{t}^{H}}{P_{t}} k_{t-1}+d_{t}\right)-\tau_{t}^{n} w_{t} n_{t}-\tau_{t}^{l} \\
& +\frac{\phi^{\tau^{c}}}{2}\left(\tau_{t}^{c}-\tau_{t-1}^{c}\right)^{2}+\frac{\phi^{\tau^{k}}}{2}\left(\tau_{t}^{k}-\tau_{t-1}^{k}\right)^{2}+\frac{\phi^{\tau^{n}}}{2}\left(\tau_{t}^{n}-\tau_{t-1}^{n}\right)^{2}+\frac{\phi^{s^{g}}}{2}\left(s_{t}^{g}-s_{t-1}^{g}\right)^{2} \\
& y_{t}^{H}=c_{t}^{H}+x_{t}+g_{t}+c_{t}^{F *}
\end{aligned}
$$




$$
\begin{gathered}
-\frac{P_{t}^{H}}{P_{t}} c_{t}^{F *}+\frac{P_{t}^{F}}{P_{t}} c_{t}^{F}+\frac{\phi^{g}}{2}\left(\frac{S_{t} P_{t}^{*}}{P_{t}} f_{t}^{g}-\frac{S P^{*}}{P} f^{g}\right)^{2}+\frac{\phi^{p}}{2}\left(\frac{S_{t} P_{t}^{*}}{P_{t}} f_{t}^{h}-\frac{S P^{*}}{P} f^{h}\right)^{2} \\
+\frac{\phi^{\tau^{c}}}{2}\left(\tau_{t}^{c}-\tau_{t-1}^{c}\right)^{2}+\frac{\phi^{\tau^{k}}}{2}\left(\tau_{t}^{k}-\tau_{t-1}^{k}\right)^{2}+\frac{\phi^{\tau^{n}}}{2}\left(\tau_{t}^{n}-\tau_{t-1}^{n}\right)^{2}+\frac{\phi^{g}}{2}\left(s_{t}^{g}-s_{t-1}^{g}\right)^{2} \\
\frac{S_{t} P_{t}^{*}}{P_{t}} \frac{P_{t-1}^{*}}{P_{t}^{*}} \frac{Q_{t-1}\left(F_{t-1}^{g}-F_{t-1}^{h}\right)}{P_{t-1}^{*}}=\frac{S_{t} P_{t}^{*}}{P_{t}} \frac{\left(f_{t}^{g}-f_{t}^{h}\right)}{P_{t}^{*}} \\
\left(P_{t}^{H}\right)^{1-\phi}=\theta P_{t-1}^{1-\phi}+(1-\theta)\left(P_{t}^{\#}\right)^{1-\phi} \\
P_{t}=\left(P_{t}^{H}\right)^{\nu}\left(P_{t}^{F}\right)^{1-\nu} \\
P_{t}^{F}=S_{t} P_{t}^{H *} \\
P_{t}^{*}=\left(P_{t}^{H *}\right)^{\nu^{*}}\left(\frac{P_{t}^{H}}{S_{t}}\right)^{1-\nu^{*}} \\
\left(\widetilde{P}_{t}^{H}\right)^{-\phi}=\theta\left(\widetilde{P}_{t-1}^{H}\right)^{-\phi}+(1-\theta)\left(P_{t}^{\#}\right)^{-\phi} \\
Q_{t}=Q_{t}^{*}+\psi\left(e^{\frac{B_{t}+S_{t} F_{t}^{g}}{P_{t}^{H} Y_{t}^{H}}-\bar{d}}-1\right)
\end{gathered}
$$

where we define $\widetilde{P}_{t}^{H} \equiv\left(\sum_{h=1}^{N}\left[P_{t}(h)\right]^{-\phi}\right)^{-\frac{1}{\phi}}$ and $\left(\frac{\widetilde{P}_{t}^{H}}{P_{t}^{H}}\right)^{-\phi}$ is a measure of price dispersion.

We thus have 22 equations in 22 endogenous variables, $\left\{y_{t}^{H}, c_{t}, c_{t}^{H}, c_{t}^{F}, n_{t}, x_{t}, k_{t}, f_{t}^{h}, m_{t}\right.$, $\left.P_{t}^{F}, P_{t}, P_{t}^{H}, P_{t}^{\#}, \widetilde{P}_{t}^{H}, w_{t}, m c_{t}, d_{t}, r_{t}^{k}, Q_{t}, f_{t}^{g}, P_{t}^{*}, R_{t}\right\}_{t=0}^{\infty}$. This is given technology, $\left\{A_{t}\right\}_{t=0}^{\infty}$, the independently set monetary and fiscal policy instruments, $\left\{S_{t}, \tau_{t}^{c}, \tau_{t}^{k}, \tau_{t}^{n}, g_{t}, \tau_{t}^{l}, b_{t}\right\}_{t=0}^{\infty}$, the rest-of-the-world variables, $\left\{Q_{t}^{*}, P_{t}^{H *}, c_{t}^{F *}\right\}_{t=0}^{\infty}$, and initial conditions for the state variables.

\subsection{Appendix 3: Decentralized equilibrium transformed (given policy)}

The transformed DE is summarized by the following 25 equations:

$$
\begin{gathered}
V_{t}=\frac{c_{t}^{1-\sigma}}{1-\sigma}-\chi_{n} \frac{n_{t}^{1+\phi}}{1+\phi}+\chi_{m} \frac{m_{t}^{1-\mu}}{1-\mu}+\chi_{g} \frac{\left(s_{t}^{g} y_{t}^{H}\right)^{1-\zeta}}{1-\zeta}+\beta E_{t} V_{t+1} \\
\beta E_{t} c_{t+1}^{-\sigma} \frac{1}{\left(1+\tau_{t+1}^{c}\right)} R_{t} \frac{1}{\Pi_{t+1}} \\
=c_{t}^{-\sigma} \frac{1}{\left(1+\tau_{t}^{c}\right)} \\
\beta E_{t} c_{t+1}^{-\sigma} \frac{1}{\left(1+\tau_{t+1}^{c}\right)} Q t T T_{t+1}^{v^{*}+\nu-1} \frac{1}{\Pi_{t+1}^{*}} \\
=c_{t}^{-\sigma} \frac{1}{\left(1+\tau_{t}^{c}\right)} T T_{t}^{v^{*}+\nu-1}\left[1+\phi^{p}\left(T T_{t}^{\nu^{*}+\nu-1} f_{t}^{h}-T T^{\nu^{*}+\nu-1} f^{h}\right)\right]
\end{gathered}
$$




$$
\begin{aligned}
& \beta c_{t+1}^{-\sigma} T T_{t+1}^{\nu-1}\left\{1-\delta-\frac{\xi}{2}\left(\frac{k_{t+1}}{k_{t}}-1\right)^{2}+\xi\left(\frac{k_{t+1}}{k_{t}}-1\right) \frac{k_{t+1}}{k_{t}}+\left(1-\tau_{t+1}^{k}\right) r_{t+1}^{k}\right\}= \\
& c_{t}^{-\sigma} T T_{t}^{\nu-1} \frac{1}{\left(1+\tau_{t}^{c}\right)}\left[1-\xi\left(\frac{k_{t}}{k_{t-1}}-1\right)\right] \\
& \chi_{m} m_{t}^{-\mu}=c_{t}^{-\sigma} \frac{1}{\left(1+\tau_{t}^{c}\right)}-E_{t} c_{t+1}^{-\sigma} \frac{1}{\left(1+\tau_{t+1}^{c}\right)} \frac{1}{\Pi_{t+1}} \\
& \chi n_{t}^{\eta}=\left(1-\tau_{t}^{n}\right) w_{t} c_{t}^{-\sigma} \frac{1}{\left(1+\tau_{t}^{c}\right)} \\
& \frac{c_{t}^{H}}{c_{t}^{F}}=\frac{\nu}{1-\nu} T T_{t} \\
& k_{t}=(1-\delta) k_{t-1}+x_{t}-\frac{\xi}{2}\left(\frac{k_{t}}{k_{t-1}}-1\right)^{2} k_{t-1} \\
& c_{t} \equiv \frac{\left(c_{t}^{H}\right)^{\nu}\left(c_{t}^{F}\right)^{1-\nu}}{(\nu)^{\nu}(1-\nu)^{1-\nu}} \\
& w_{t}=m c_{t}(1-a) A_{t} k_{t-1}^{a} n_{t}^{-a} \\
& \frac{1}{T T_{t}^{1-v}} r_{t}^{k}=m c_{t} a A_{t} k_{t-1}^{a-1} n_{t}^{1-a} \\
& d_{t}=\frac{1}{T T_{t}^{1-v}} y_{t}^{H}-\frac{1}{T T_{t}^{1-v}} r_{t}^{k} k_{t-1}-w_{t} n_{t} \\
& z_{t}^{1}=\frac{\phi}{(\phi-1)} z_{t}^{2} \\
& y_{t}^{H}=\frac{1}{\Delta_{t}} A_{t} k_{t-1}^{a} n_{t}^{1-a} \\
& b_{t}+m_{t}+T T_{t}^{v+v^{*}-1} \frac{f_{t}^{T T}}{T T_{t}^{\nu^{*}}}=\frac{\phi^{g}}{2}\left(T T_{t}^{\nu^{*}+\nu-1} \frac{f_{t}^{T T}}{T T_{t}^{\nu^{*}}}-T T^{\nu^{*}+\nu-1} \frac{f^{T T}}{T T^{\nu^{*}}}\right)^{2}+R_{t-1} \frac{1}{\Pi_{t}} b_{t-1}+\frac{1}{\Pi_{t}} m_{t-1} \\
& +Q_{t-1} T T_{t}^{v+v^{*}-1} \frac{1}{\Pi_{t}^{*}} \frac{f_{t-1}^{T t}}{T T_{t-1}^{\nu^{*}}}+\frac{1}{T T_{t}^{1-v}} s_{t}^{g} y_{t}^{H}-\tau_{t}^{c}\left(\frac{1}{T T_{t}^{1-v}} c_{t}^{H}+T T_{t}^{v} c_{t}^{F}\right)-\tau_{t}^{k}\left(r_{t-1}^{k} \frac{1}{T T_{t}^{1-v}} k_{t-1}+d_{t}\right)-\tau_{t}^{n} w_{t} n_{t}-\tau_{t}^{l} \\
& +\frac{\phi^{\tau^{c}}}{2}\left(\tau_{t}^{c}-\tau_{t-1}^{c}\right)^{2}+\frac{\phi^{\tau^{k}}}{2}\left(\tau_{t}^{k}-\tau_{t-1}^{k}\right)^{2}+\frac{\phi^{\tau^{n}}}{2}\left(\tau_{t}^{n}-\tau_{t-1}^{n}\right)^{2}+\frac{\phi^{s}}{2}\left(s_{t}^{g}-s_{t-1}^{g}\right)^{2} \\
& y_{t}^{H}=c_{t}^{H}+x_{t}+s_{t}^{g} y_{t}^{H}+c_{t}^{F *} \\
& T T_{t}^{\nu^{*}+\nu-1}\left(\frac{f_{t}^{T T}}{T T_{t}^{\nu^{*}}}-f_{t}^{h}\right)=-T T_{t}^{\nu-1} c_{t}^{F *}+T T_{t}^{\nu} c_{t}^{F}+Q_{t-1} T T_{t}^{\nu^{*}+\nu-1} \frac{1}{\Pi_{t}^{*}}\left(\frac{f_{t-1}^{T T}}{T T_{t-1}^{\nu^{*}}}-f_{t-1}^{h}\right) \\
& +\frac{\phi^{p}}{2}\left(T T_{t}^{\nu^{*}+\nu-1} f_{t}^{h}-T T^{\nu^{*}+\nu-1} f^{h}\right)^{2}+\frac{\phi^{g}}{2}\left(T T_{t}^{\nu^{*}+\nu-1} \frac{f_{t}^{T T}}{T T_{t}^{\nu^{*}}}-T T^{\nu^{*}+\nu-1} \frac{f^{T T}}{T T^{\nu^{*}}}\right)^{2} \\
& +\frac{\phi^{\tau^{c}}}{2}\left(\tau_{t}^{c}-\tau_{t-1}^{c}\right)^{2}+\frac{\phi^{\tau^{k}}}{2}\left(\tau_{t}^{k}-\tau_{t-1}^{k}\right)^{2}+\frac{\phi^{\tau^{n}}}{2}\left(\tau_{t}^{n}-\tau_{t-1}^{n}\right)^{2}+\frac{\phi^{s}}{2}\left(s_{t}^{g}-s_{t-1}^{g}\right)^{2}
\end{aligned}
$$




$$
\begin{aligned}
& \left(\Pi_{t}^{H}\right)^{1-\phi}=\theta+(1-\theta)\left(\Theta_{t} \Pi_{t}^{H}\right)^{1-\phi} \\
& \frac{\Pi_{t}}{\Pi_{t}^{H}}=\left(\frac{T T_{t}}{T T_{t-1}}\right)^{1-\nu} \\
& \frac{T T_{t}}{T T_{t-1}}=\frac{\epsilon_{t} \Pi_{t}^{H *}}{\Pi_{t}^{H}} \\
& \frac{\Pi_{t}^{*}}{\Pi_{t}^{H *}}=\left(\frac{T T_{t-1}}{T T_{t}}\right)^{1-\nu^{*}} \\
& \Delta_{t}=\theta \Delta_{t-1}\left(\Pi_{t}^{H}\right)^{\phi}+(1-\theta)\left(\Theta_{t}\right)^{-\phi} \\
& Q_{t}-1=Q_{t}^{*}-1+\psi\left(e^{\left(\frac{T T_{t}^{\nu+\nu^{*}-1} \frac{f_{t}^{T T}}{T T_{t}^{\nu^{*}}+b_{t}}}{T T_{t}^{\nu-1} y_{t}^{H}}-\bar{d}\right)}-1\right) \\
& z_{t}^{1}=\Theta_{t}^{1-\phi} y_{t} T T_{t}^{\nu-1}+\beta \theta E_{t} \frac{c_{t+1}^{-\sigma}}{c_{t}^{-\sigma}} \frac{1+\tau_{t}^{c}}{1+\tau_{t+1}^{c}}\left(\frac{\Theta_{t}}{\Theta_{t+1}}\right)^{1-\phi}\left(\frac{1}{\Pi_{t+1}^{H}}\right)^{1-\phi} z_{t+1}^{1} \\
& z_{t}^{2}=\Theta_{t}^{-\phi} y_{t} m c_{t}+\beta \theta E_{t} \frac{c_{t+1}^{-\sigma}}{c_{t}^{-\sigma}} \frac{1+\tau_{t}^{c}}{1+\tau_{t+1}^{c}}\left(\frac{\Theta_{t}}{\Theta_{t+1}}\right)^{-\phi}\left(\frac{1}{\Pi_{t+1}^{H}}\right)^{-\phi} z_{t+1}^{2}
\end{aligned}
$$

We thus have 25 equations in 25 endogenous variables, $\left\{V_{t}, y_{t}^{H}, c_{t}, c_{t}^{H}, c_{t}^{F}, n_{t}, x_{t}, k_{t}, f_{t}^{h}\right.$, $\left.m_{t}, T T_{t}, \Pi_{t}, \Pi_{t}^{H}, \Theta_{t}, \Delta_{t}, w_{t}, m c_{t}, d_{t}, r_{t}^{k}, Q_{t}, f_{t}^{T T}, \Pi_{t}^{*}, z_{t}^{1}, z_{t}^{2}, R_{t}\right\}_{t=0}^{\infty}$. This is given technology, $\left\{A_{t}\right\}_{t=0}^{\infty}$, the independently set policy instruments, $\left\{\epsilon_{t}, \tau_{t}^{c}, \tau_{t}^{k}, \tau_{t}^{n}, s_{t}^{g}, s_{t}^{l}, b_{t}\right\}_{t=0}^{\infty}$, the rest-ofthe-world variables, $\left\{Q_{t}^{*}, \Pi_{t}^{H *}, c_{t}^{F *}\right\}_{t=0}^{\infty}$, and initial conditions for the state variables.

\subsection{Appendix 4: Determinacy areas}

The determinacy areas and how they are affected by feedback policy coefficients are shown below: 
Figure A4: Determinacy areas and feedback policy coefficients
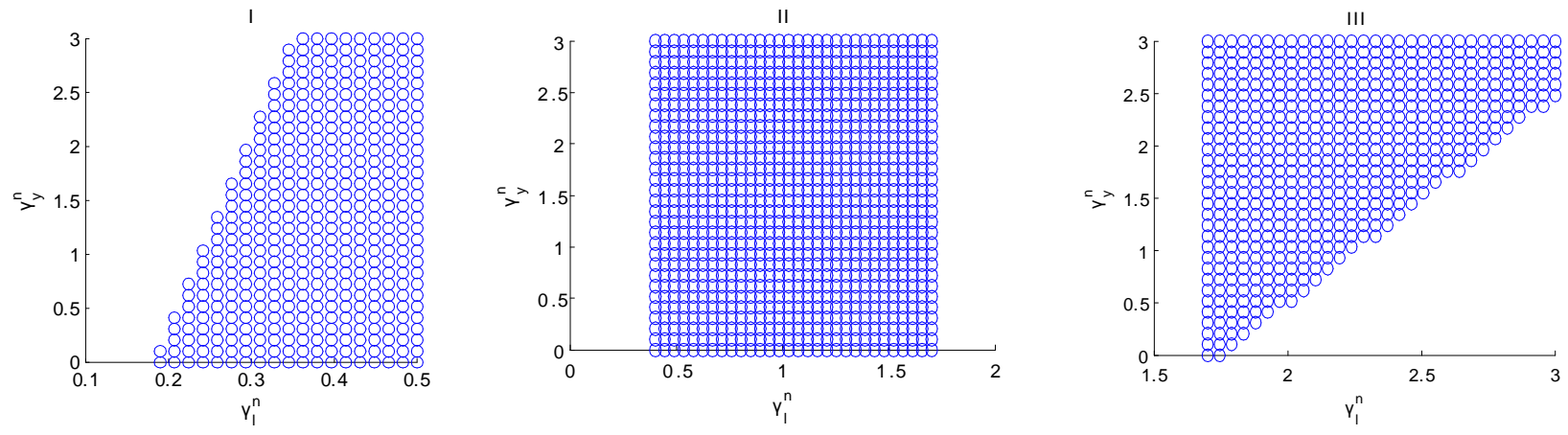